Bull. Fac. Agric., Cairo Univ., 69: 131 -146 (2018).

\title{
ECOSYSTEM ANALYSIS OF A PART OF THE WADI MOHAMMADI WITHIN THE WESTERN DESERT OF IRAQ
}

(Received:10.4.2018)

\author{
By \\ A. A.M. Alalwany, M. O. Mousa and S. A. Salim \\ Center for Desert Studies, Iraq Anbar University,
}

\begin{abstract}
Given the shortage of studies of the distribution of plant communities within the study area, the present research was conducted to identify the composition of natural vegetation and forms of growth and geographical biogenic life in a part of the watershed of Wadi Al-Muhammadi in the period between autumn 2016 and spring 2017. It was found that the region contains several plants, whether perennial or annul, have been identified based on the characteristics of the dominant plant community random Quadrate method, using sixteen squares covered the study. Then natural plant growth was estimated. Distribution of plant communities varied depending on the geomorphology unit of the area, which was divided into following:- the relatively high are: (plateau), the terraces, floodplain, and the bottom of the valley and on the characteristics of the soils dominant and soil salinity and the soil moisture. 36 plant species belonging to 18 families were recorded life forms were Therophytes and Chamaephytes and plants, all within the climate component (Middle Saharo- Sendian sub-region) based on the classification of regions biogeography map (Biogeographically regions) of the study area. The most representative families are Gramineae and Compositae, Chenopodiaceae . A large proportion of these species were abundant within the wetlands, especially in the course of output and schedules for artesian wells flowing waters toward downstream of the main wadi, particularly the valley, and the moisture salts and content of soils first were determinants within the study area as well as geological formations located within the region. Most of the plant species recorded were in danger of degradation and extintion. This region is exposed to human and environmental factors and security threats. These factors are: overgrazing, the cutting of shrubs with herbs as well activity quarries for building materials circulating within the region within the illegal activities of the region's population,It reems that the reason for the survival of these plant communities and spread over the seasons of the year is due to availability of the necessary moisture from artesian water flow for germination through the collector within the valley and the flow of this water stream towards the main valley.
\end{abstract}

Key words: plant communities. wadi Al-muhammadi. sulfur water. ecosystem. western desert. 


\title{
تحليل النظام البيئي لجزء من وادي المحمدي ضمن الصحراء الغربية من العراق
}

\section{عبدالكريم احمد مخيلف العلواني- محمد عثمان موسى- سيف الدين عبدالرزاق سالم}

\author{
مركز دراسات الصحر اء - جامعة الانبار - العر اق
}

\begin{abstract}
ملخص

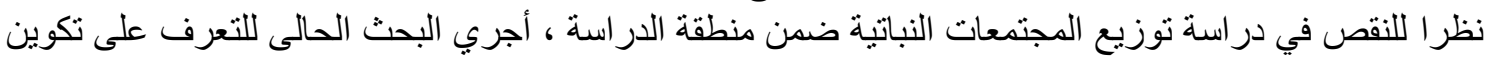

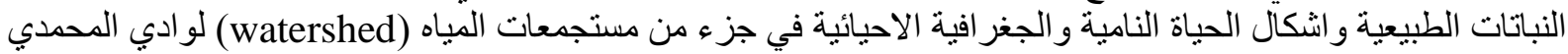

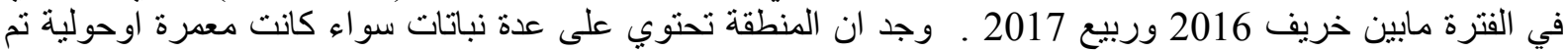

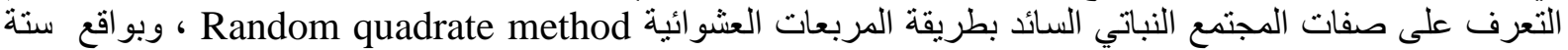

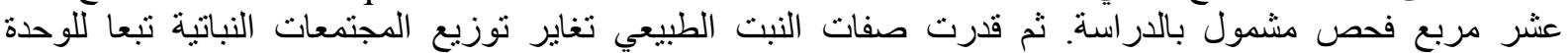

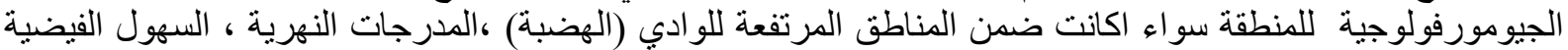

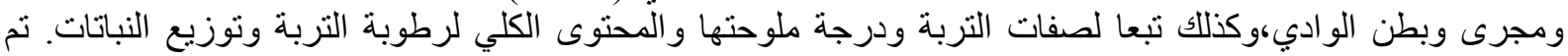

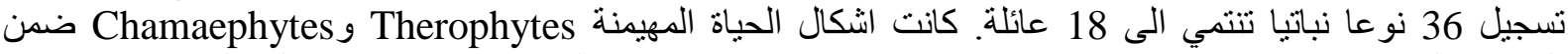

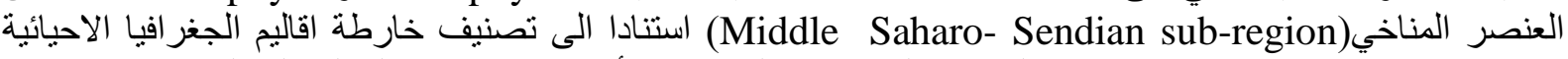

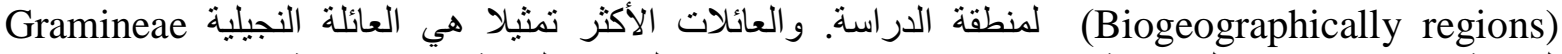

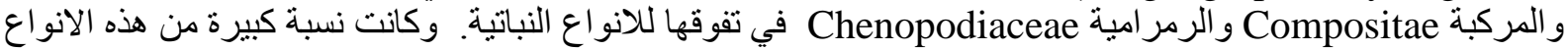

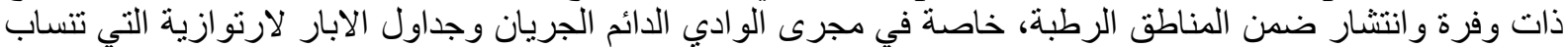

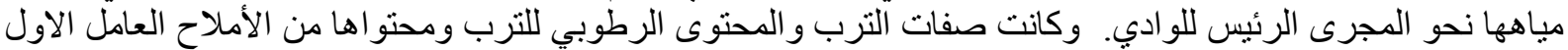

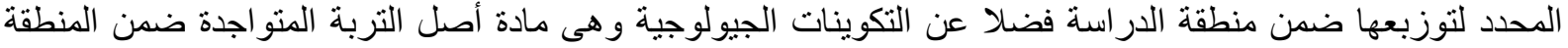

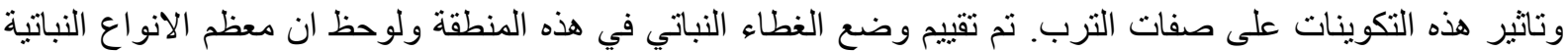

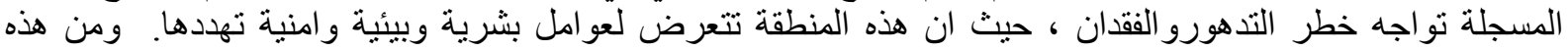

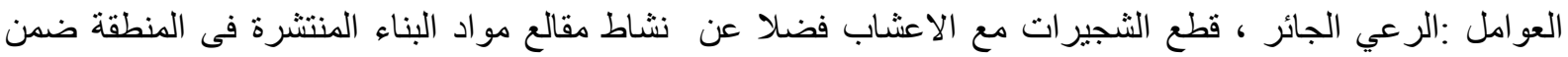

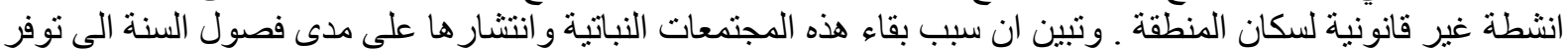

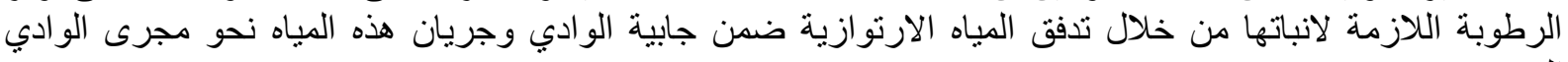

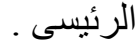

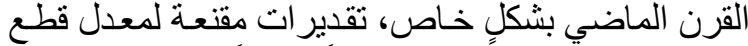

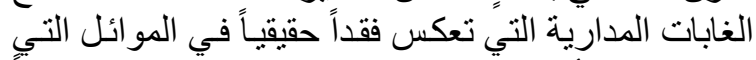

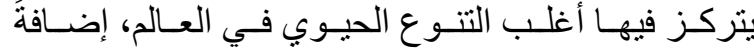

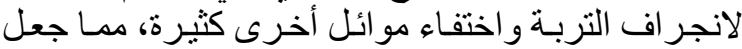

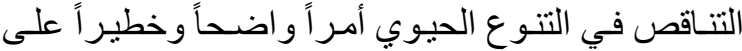

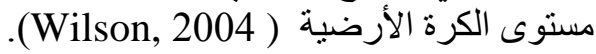

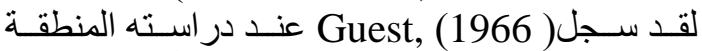

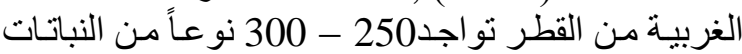

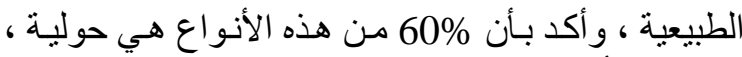

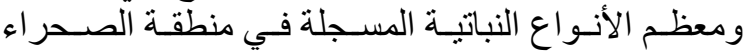

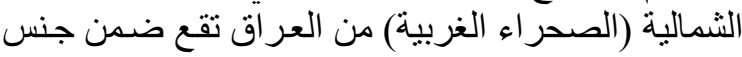

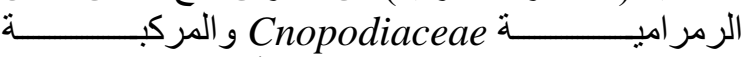
Composita التاليـة:الحمض Haloxylon salicornicum و الرمـث Artemisia herba-alba و والثيح

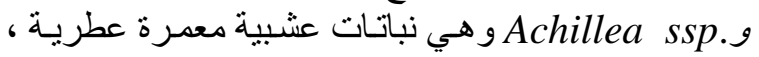

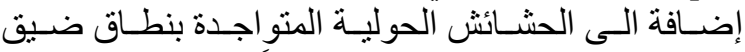
وخاصة .Stipa grostis ssp فضلاً عن الحلفـا و الثـائع S. plumose

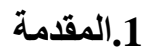

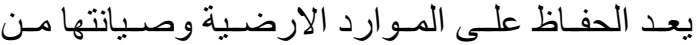
أولويـات سياسـات وبر امج التنميـة المطبقـة حاليـا في دول التول

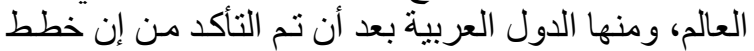

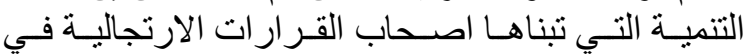

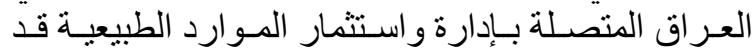

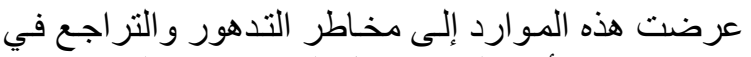

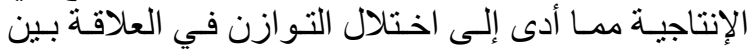
الإحتياجات الإنسانية و البيئه.

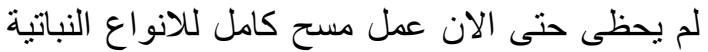
الموجودة بالمناطق الجافة الصحر اوية باستثناء الدراسة الإنة

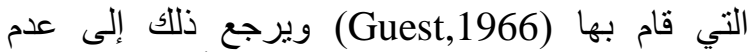
الاكتراث والافتقار الى الثقافة النباتية لأصحاب القراب الترار

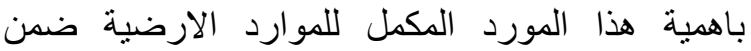

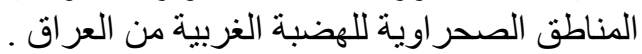

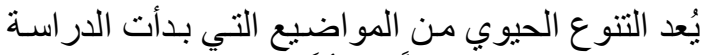

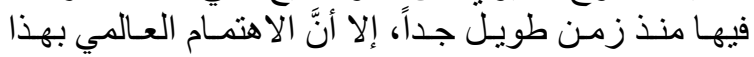

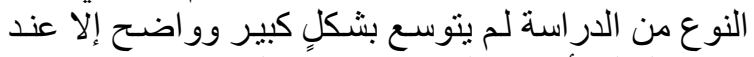

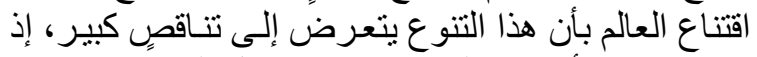

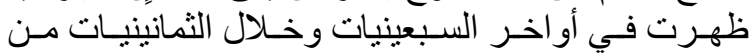




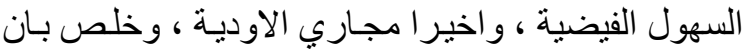

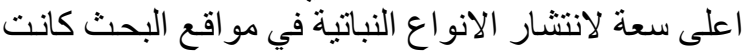

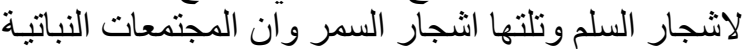

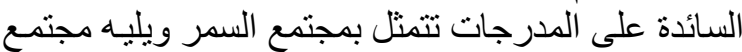

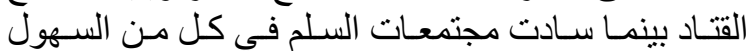

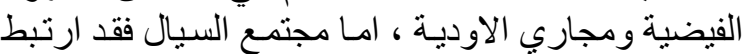

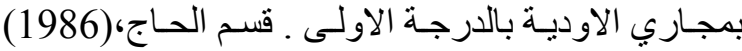

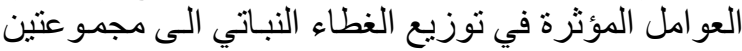

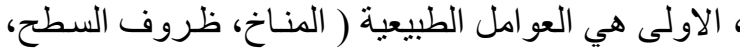

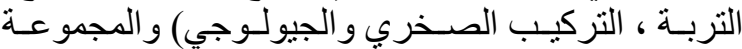

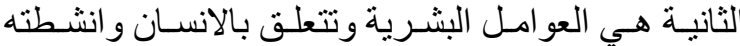

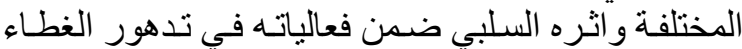

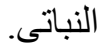

ومـن الأسـباب التى على أساسـها تم إختبارمنطقة

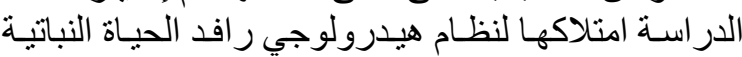

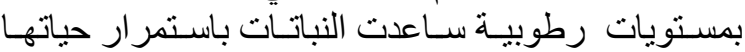

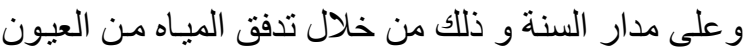

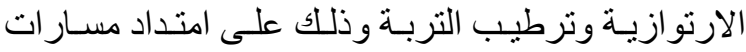

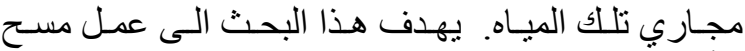

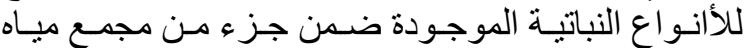

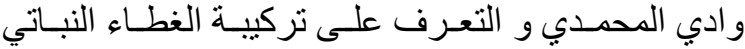

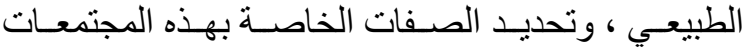

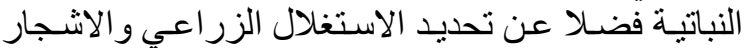

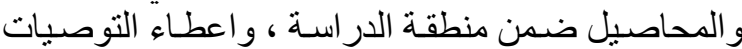

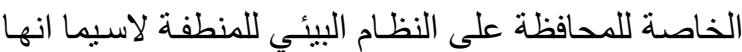

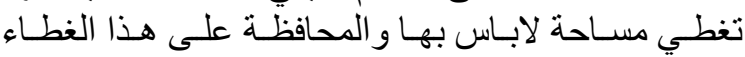

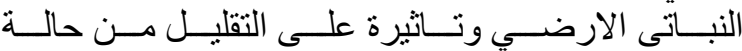

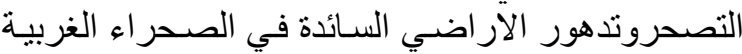
من العر اق و المحافظة على سطح الأرض من الإنجر افت.

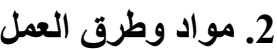

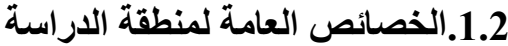 1.1.2 1.2 اختيار منطقة الاراسة الغنة}

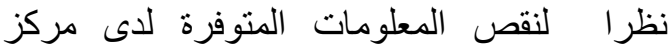

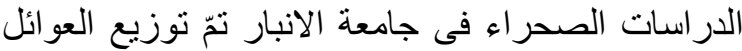

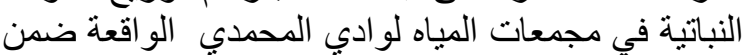

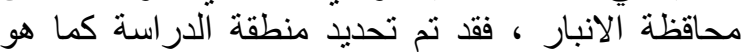

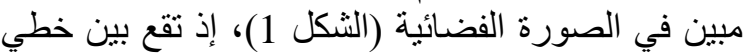

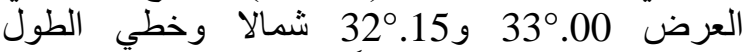

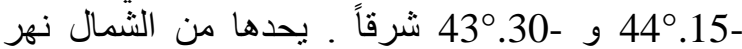

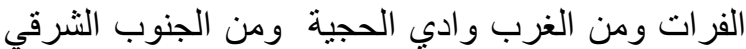

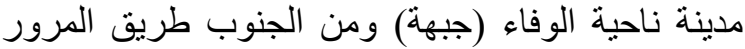
السريع بغداد ـ الاردن ـ ـ تبلغ المساحة الكلية للمنطقة المنية

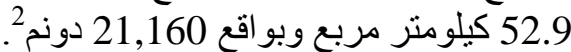

2.1.2 جيومورفولوجية منطقة الدراسة صنفت الوحدات الجيومورفية في المنطقة من قبلة الوبلة Sissakian,et.al.(1997) على اساس العوامل المسبية في تكوينها (اصل نشأتها) وشملت مايلي :الوحدات الناتجة النانة
إن طبيعـة توزيـع وانتشـار النبـت الطبيعـي في هـذا

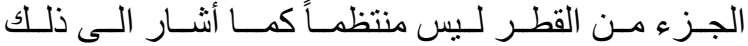
.Agnew(1960)

وقد أثـار Kaul and Al-Mufti (1974) عند

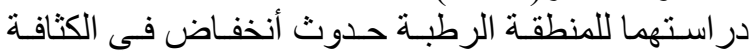

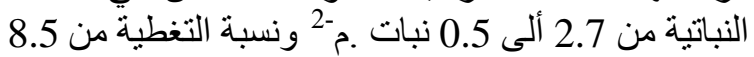

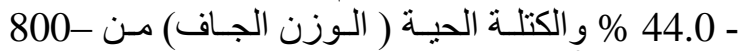
5200

عرف (1975) عaurence et al. الطبيعية بأنها تلك الأراضي الثناسعة غبر المناسبة

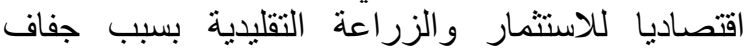

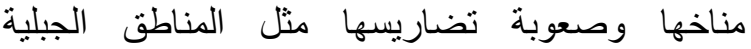
و السبخات وتتألف من حشائش ونجيليات وشجير التئي ات و التي التي تعتبر المصدر الرئيسي لغذاء الحيوانات المستأنسة

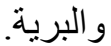
أثثر التدهور في الأراضي على التتوع الحيوي النباتي

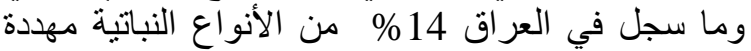

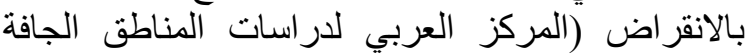

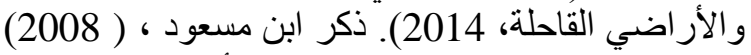

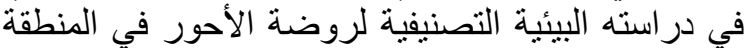

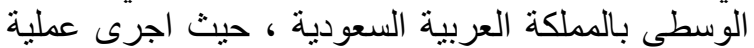

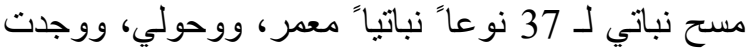

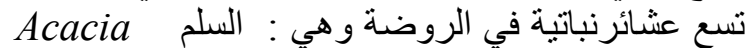

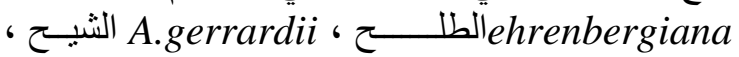

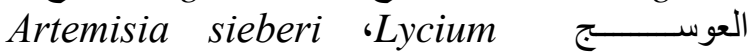

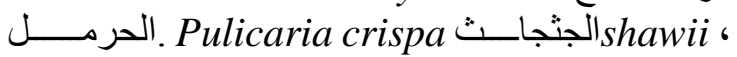
، Zilla spinosa الســـHazya stricta السدر nummularia Ziziphus.

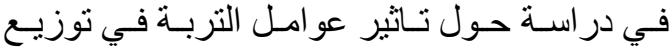

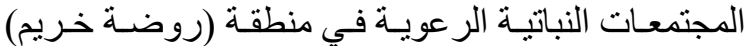

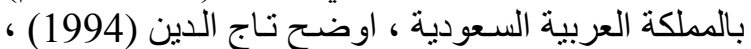

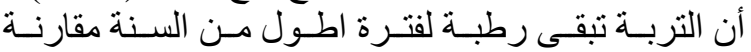

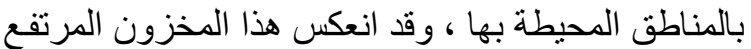

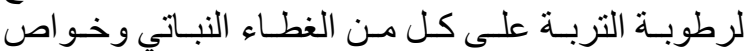

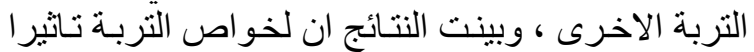

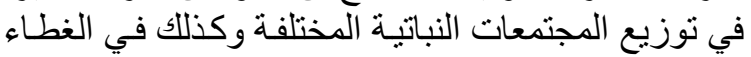

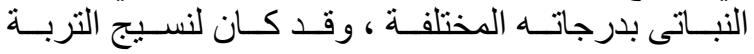

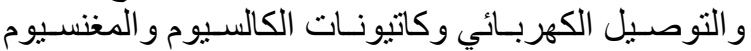

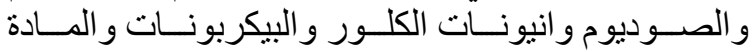

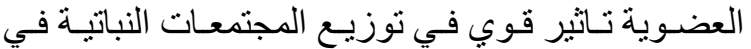

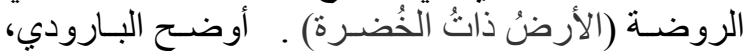

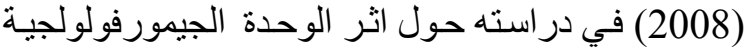

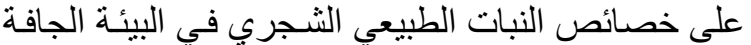

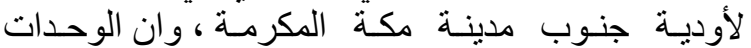

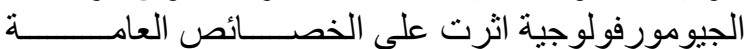

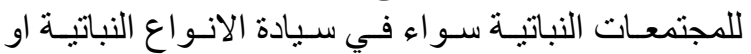

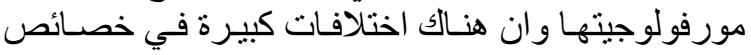

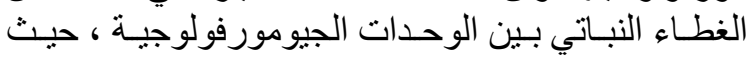

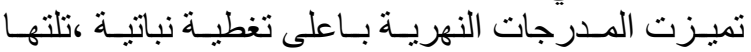


وتتو اجد مستويات مختلفة من المدرجات النهرية بمحاذاة

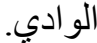

4.2.جيولوجية منطقة الاراسة

من الناحية التركيبية تقع منطقة الدراسة ضمن النطاق الانتقالي بين الرصيف الريف المستقر(Stable shelf) والرصيف غير المستقر (Unstable shelf) وتحديدا ضمن نطاق فالق ابو الجير. تقع منطقة الدراسة من الرن طبقات فى التركيب الجيولوجي المئن المئد من المايوسين المين وحتى العصر الحديث وهي كالاتي :

Nfayil تكوين النفايل(المايوسين الاوسط )

Formation (Middle Miocene)

لقد اضيف تكوين النفايل حديثاً الى العمود الطبقى السابق

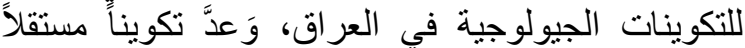
Varoujan and بذاته وغير تابع إلى تكوين الفينة . (Mohammed 2007

ويظهر هذا التكوين في مناطق متفرقة ضمن منطقة الاراسة وفي المناطق التي تعد منطقة تقسيم المياه بين الإنين الأحواض ألمائية لأودية الأخضر وحقان وقلان و والفحيمي

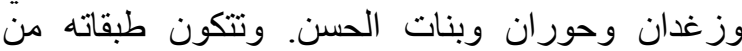

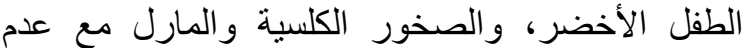

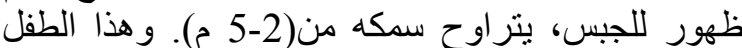
عادة تعلوه طبقة الصخور الكلسية الذي يكون جيد التيد التطبق

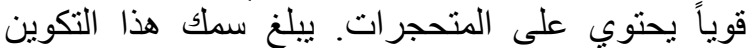

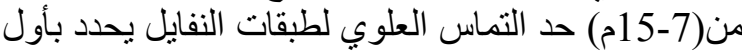
ظهور للصخر الطيني الأحمر والذي يليه الجبس الكليس الفيلية

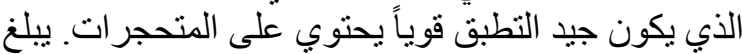

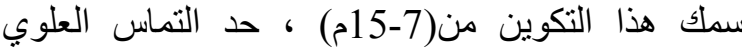
لطبقات النفايل يحدد بأول ظهور للصخر الطيني الأحمر الطئري

ترسبات العصر الرباعي Quaternary Sediment (البليستوسين والهولوسين)

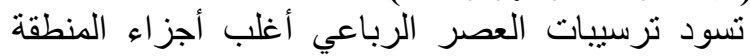
والتي تعود بالاصل إلى البليستوسين و الهولوسين وتقسم التياع التئ

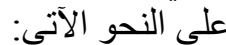
ـ ترسبات المدرجات Terraces Sediment من عصر الآثر

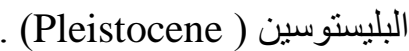
- الأراضى المتبقية Residual Soil من عصر (Plei

بليستوسين-هولوسين (Pleistocene - Holocene). - ترسيبات المنحدرات Slope Sediment من عصر (Pلين

بليستو سين-هولوسين (Pleistocene - Holocene). ـ الرواسب المليئة للوديان Valley Fill Sediment من لـونين عصر هولوسين (Holocene)، تكون هذه التران الترسبات فتاتية مختلفة الاحجام تتر اوح بين الحصى الخشن و والرمل الترن الناعم وجلاميد من صخور الكلس تترسب في في بطون التون الوديان عند نهاياتها. وفي قاع واع الوديان العميقة يكون

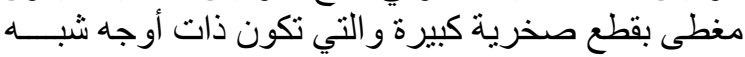

بفعل عو امل التعرية وبتاثير تركيبي وتتشل المصاطب

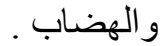

ـ الوحدات الناتجة بفعل عو امل التعرية التفاضلية (عوامل مناخية كالامطار والسيول) مثل وحدة الاراضي الني الوعرة (Pediment) ـ الوحدات الناتجة من عوامل التعرية والترسيب للمياه السطحية (الانهارو الوديان) وتتشمل السهل الفيضي plain الوديان و المنخفضات (Valley fill sediments and Depression)ـ الوحدات الناتجة من عوامل التعرية الفيزيائية و الكيميائية ـ للصخور بفعل المياه السطحية (وحدات الونية الوديان

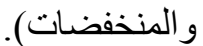
ـ الوحدات الناتجة من التبخير متمثلة فى الأراضى الملحية

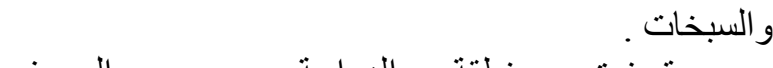

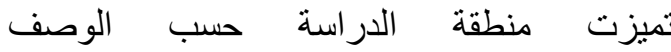

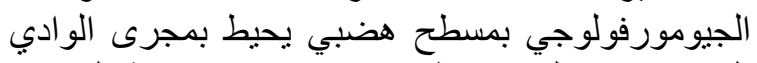

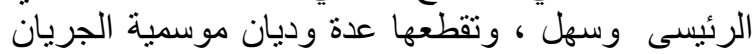

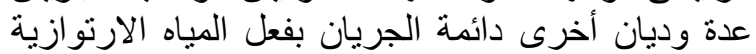

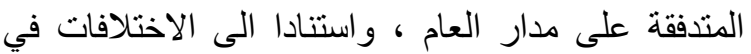

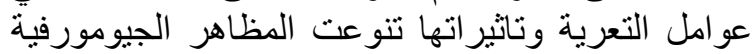
في المنطقة وكالاتي : 2.

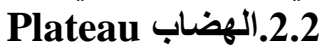

تتواجد الهضاب على جانبي مجرى الوادي على ملى الوابل

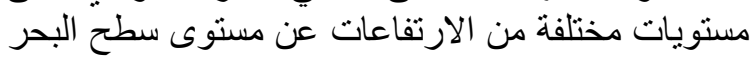

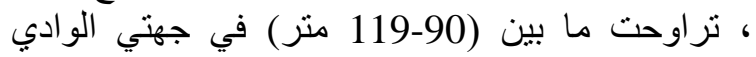
وتتميز هذه الهضاب بالحافات التدريجية ، ومغطاة

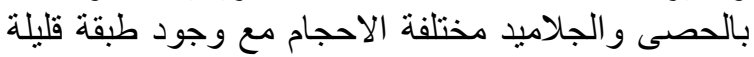

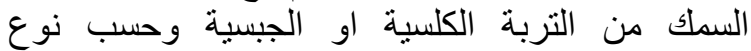
الصخور الام المشكلة للهضبة فضلا عن تنوع النمة

$$
\text { تصريف الاودية . }
$$

المصاطب الصخرية الصنية

تتواجد المصاطب الصخرية الصنية في منطقة الهضاب الجبسية

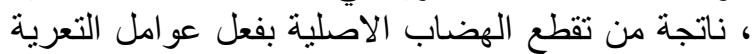

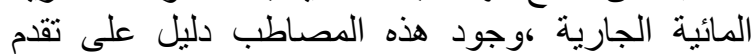
التعرية و اثر ها على سطح الهضية الهود وكيفية تثكيل الوديان 3.2. السهول يوجد ضمن منطقة الدر اسة جزء عا من سهل وادي

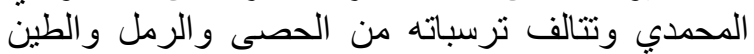

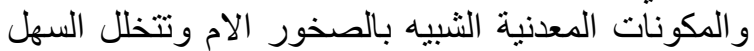

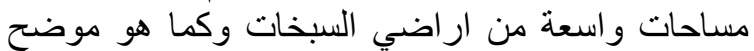

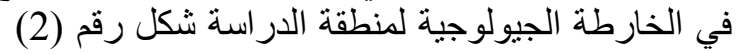

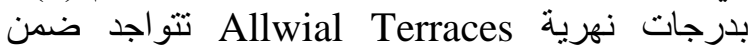
منطقة الدراسة وهي الاشكال الارضية الناتجة عن تعاقب التب التبر

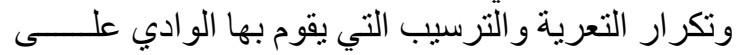

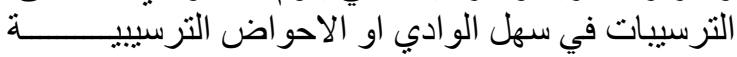




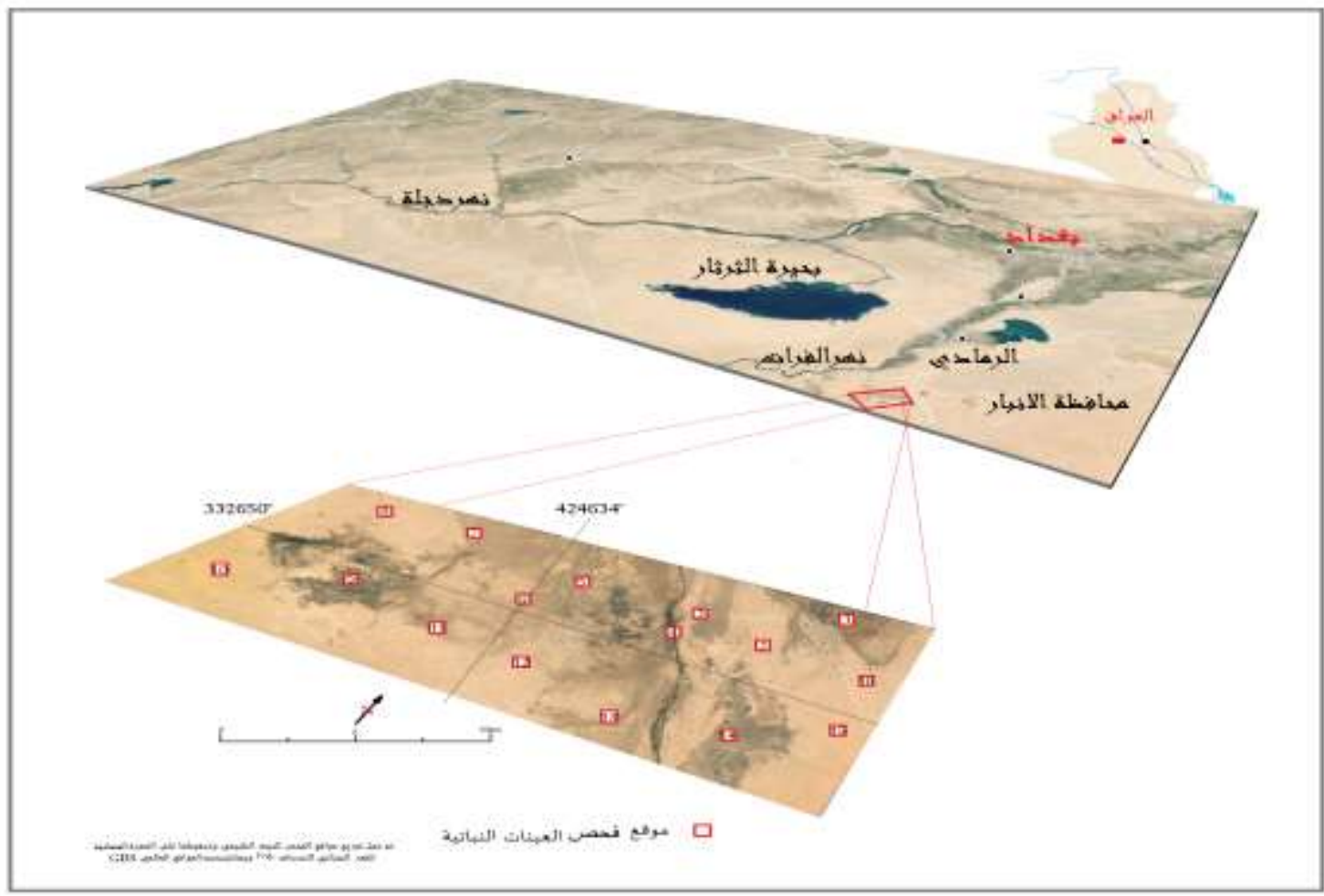

شكل (1) : توزيعات مواقع مسح العينات النباتية لمنطقة الاراسة مسقطة على الصورة الفضائية للقمر الصناعي ( Landsat US . ( Dept. of state geographer -2015

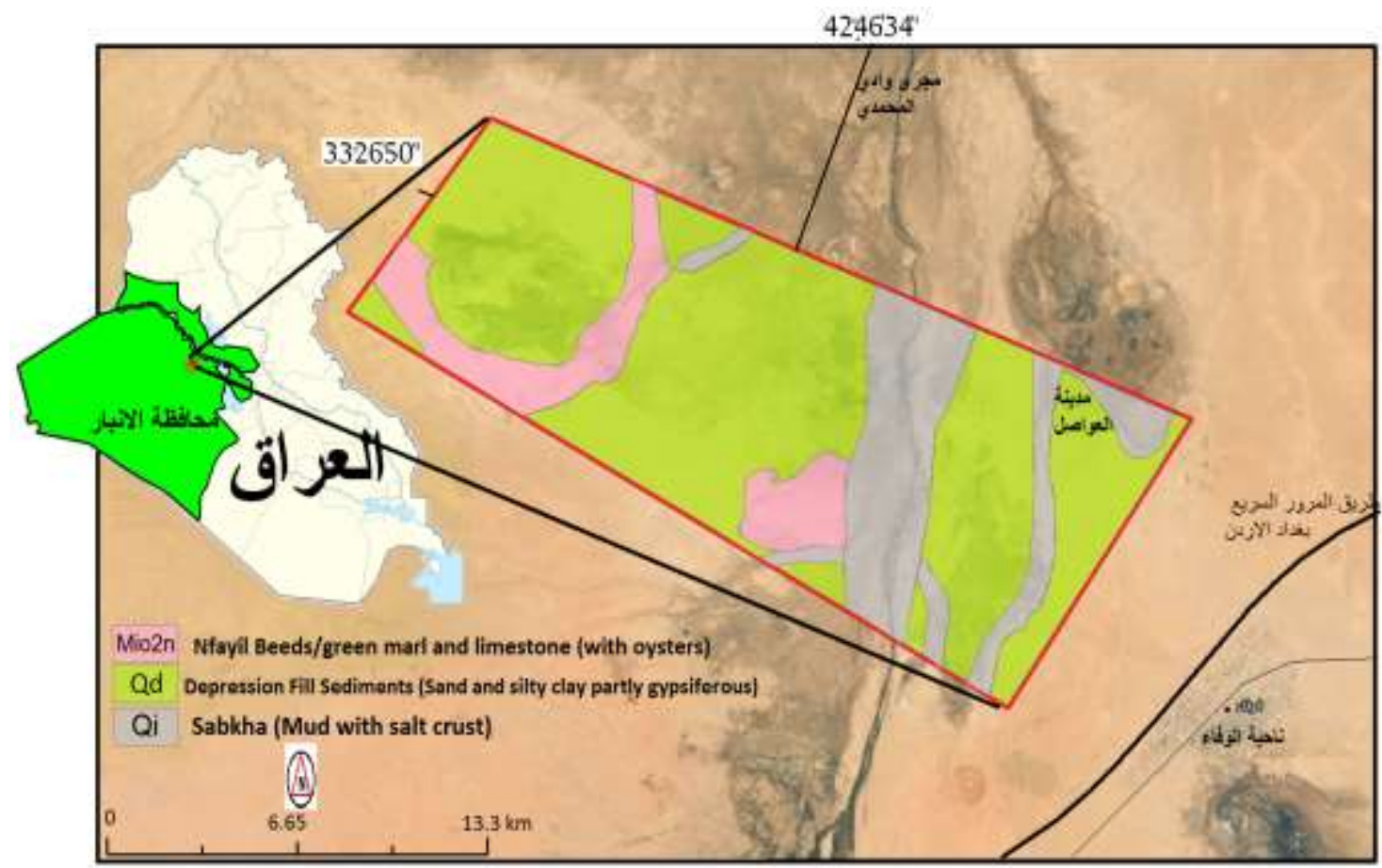

شكل (2) : صورة فضائية مسقطة عليها خارطة التكوينات الجيولوجية لمنطقة الدراسة

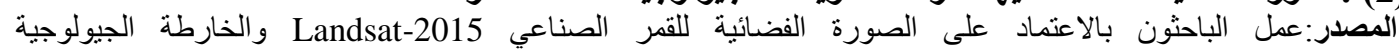

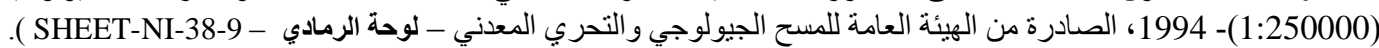


ـ الاشعاع والسطوع الثمسي Solar radiation and brightness

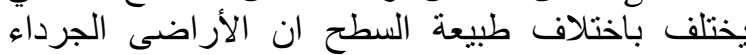

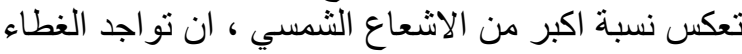

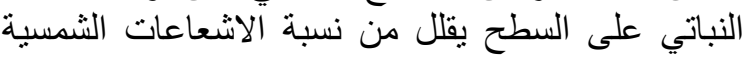

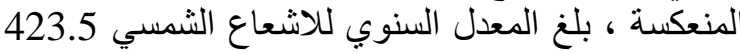

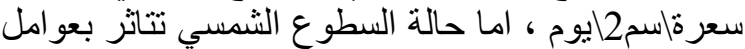

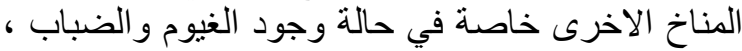
بلغ المعدل السنوي للسطوع الثنمسي لمنطقة الدراسة 8.9

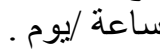

6.2. 6.العمل الحقلي لجمع العينات النباتية

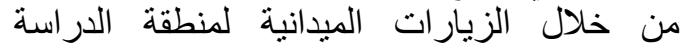
Landsat US ) استخدمت صورة فضائية للقمر الصناعية الصنية

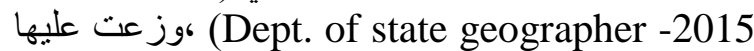
مربعات الدراسة المنوافقة مع المساحة الكلية لمنطقة

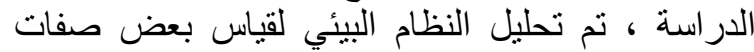

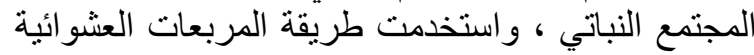
وهذه الطريقة (Random quadrate method) وصفها كل من (Cain and Castro 1959) ، وتستخدم

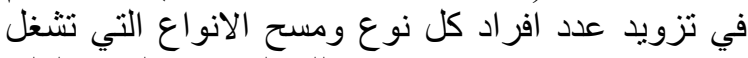

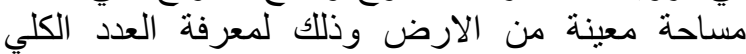

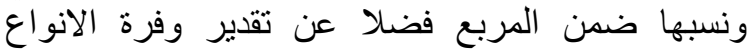

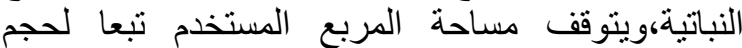

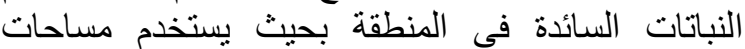
صغيرة في حالة النباتات الصغيرة الحجم ومساحات كبيرة

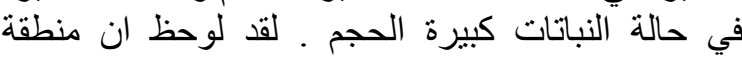
الدر اسة ينتشر فيها الثجير ات واتلات الاعشاب لذلك تم استخدام

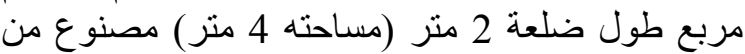
البلاستلك، وتم مسح النباتات في 16 وحدة فحص تجرئ تجريبية اخذت عشو ائيا لكل موقع.

تم تحديد أنواع النباتات الطبيعية الموجودة في كل

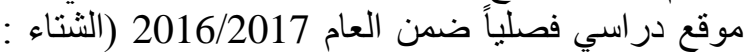
أشهر كانون الأول- كانون الثاني- شباط ) و و (الربيع : الثناء :

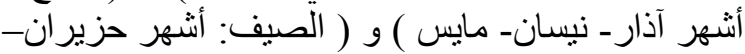

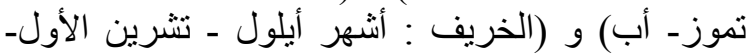

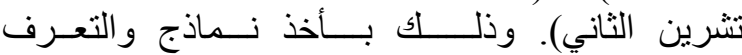

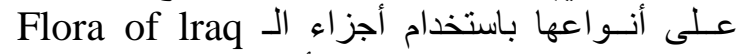

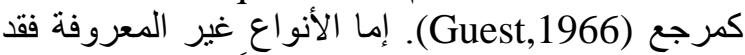

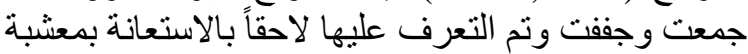
كلية التربية للعلوم الصرفة في قسم علوم الحياة - جامعة التانة

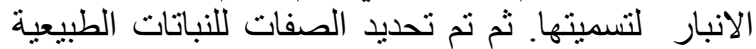

Barbour et al. حسب الطرق الواردة في (1980)

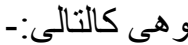

أ- عدد النباتات الموجودة ضمن كل مربع وأنواعها مع التع

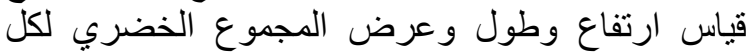

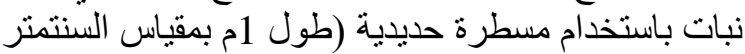
و المليمنر) وكذللك شريط القياس.
مستديرة، مع خليط من الرمل و الحصى الناعم،اما

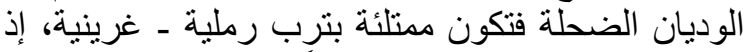
يكون في بعض المناطق جبسياً. سمك هذه الترني الترسبات

يختلف اختلافاً كبيراً إذ يتراوح ما بين(-0.5-2075)

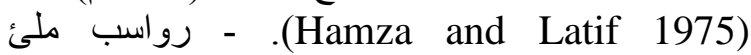
المنخفضات Depression Fill Sediment من عصر

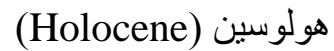

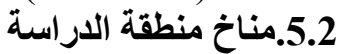

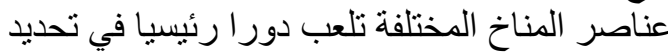
القدرة الانتاجية الطبيعية في المناطق الجافة وشبه الّافية ،

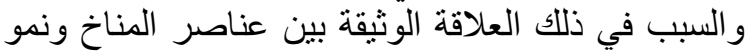

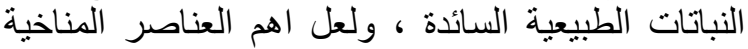

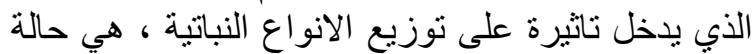

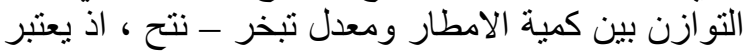

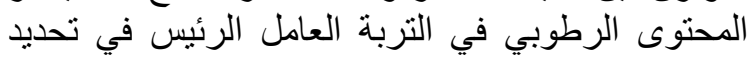

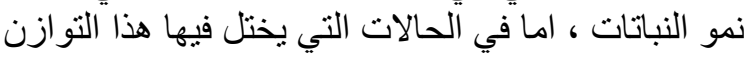

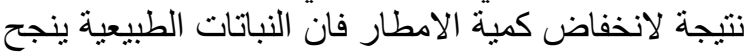

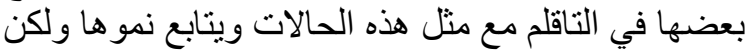

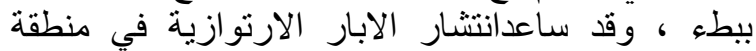

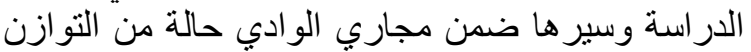

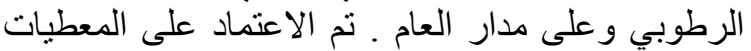

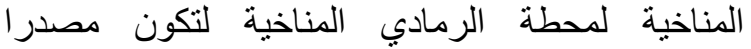
للمعلومات و البيانات المناخية للار اسة وللمادية اللمدة 19812010 ـ تقع منطقة الدراسة في القسم الجنوبي من المنطقة ولاتية

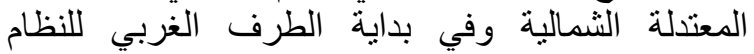

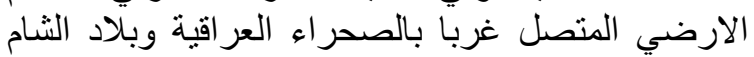

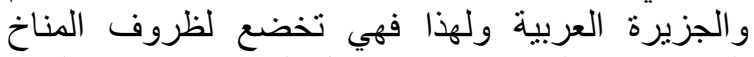
الصحراوي الجاف وبدرجة القل لمؤثرات مناخ البرات البحر

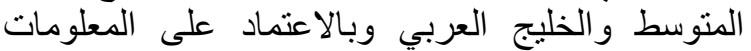
المناخية لمنطقة البحث الجدول (1) الثكل (3) نستخلص الميل

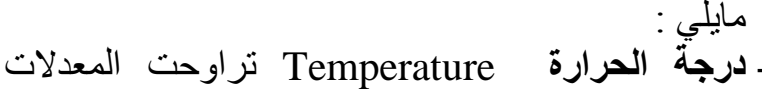

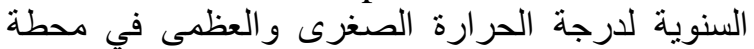
الانو اء الجوية لمنطقة البحث (الرمادي) وللفترة (1981-

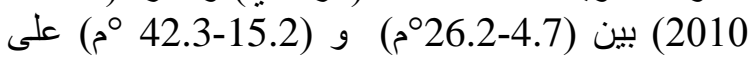

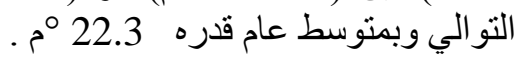

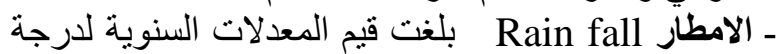

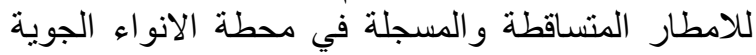

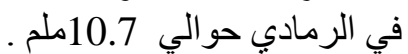
ـ التبخر : Evaporation بلغت فيم الرمادي المعدلات السنوية للتبخر و المسجلة في محطة الرمادي حوالي

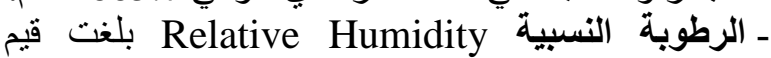
المعدلات السنوية للرطوبة النسبية الربية والمبلة الربلة في محطة

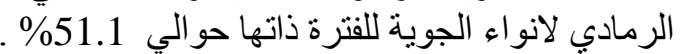
ـ الرياح wind : تسود منطقة الدراسة الرئة الرياح الثمالية

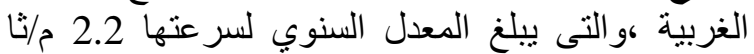
وكما موضح في الجدول (1). 


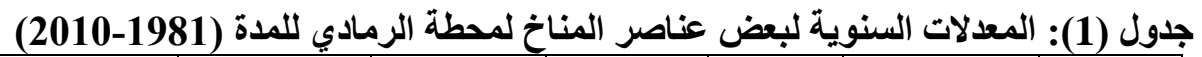

\begin{tabular}{|c|c|c|c|c|c|c|c|c|}
\hline التبخر(ملم) & $\begin{array}{l}\text { الرطبية } \\
\text { الرطبة) } \\
\text { (\%) }\end{array}$ & سعرةاسمّائيوم & (الثمسئي & النسبية (\%) & (الرياحة & الامطار & (درجة مئوية) & المحطات \\
\hline 2665.7 & 51.1 & 423.5 & 8.9 & 51.1 & 2.2 & 110.7 & 22.3 & الرمادى \\
\hline
\end{tabular}

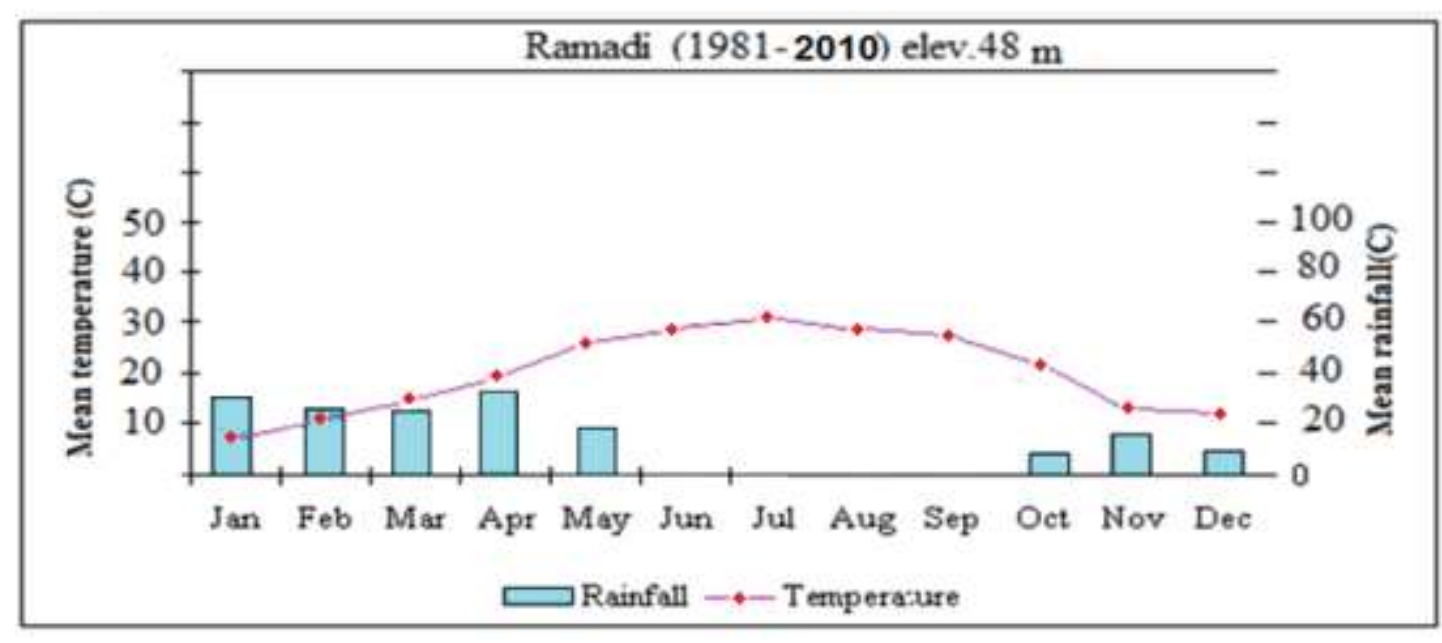

شكل (3): المخططات المناخية لمحطة الانواء الجوية لمدينة الرمادي

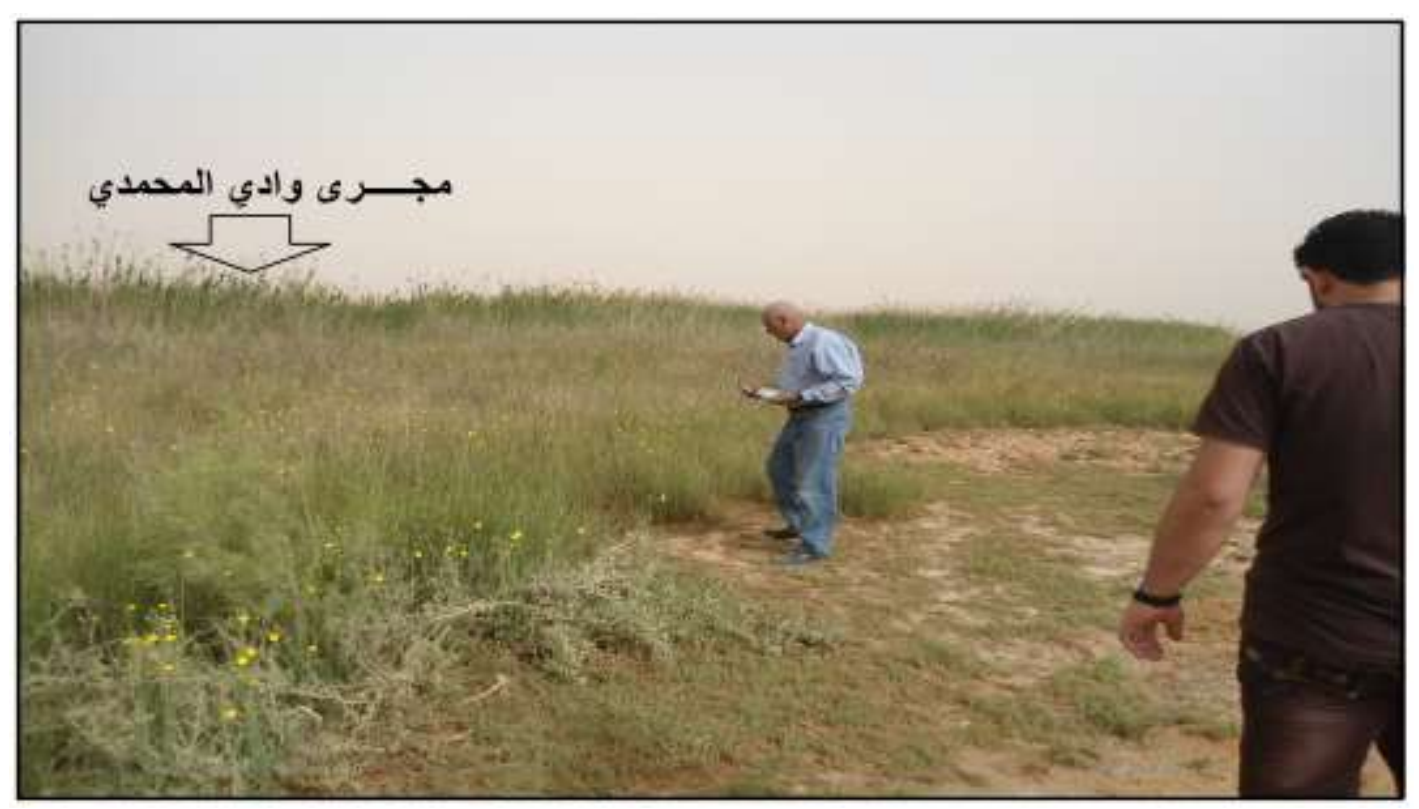

شكل (4) : يمثل كثافة النباتات الطبيعية في مجرى الوادي- 2017 
2.3. دراسة صفات النبات الطبيعي لمنطقة الدراسة

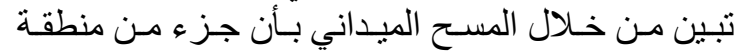

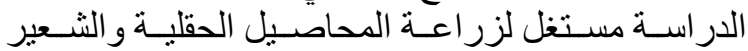
و الـذرة الصـفر اء ومحاصـيل بسـتانية مثنل اثــار النخيل

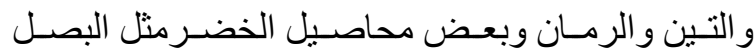
و التي تروى على مياه الآبار المنتشرة فئها.

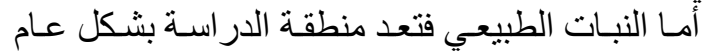

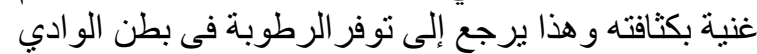

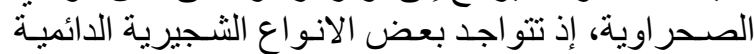

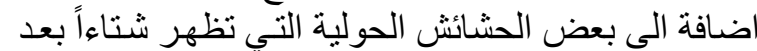

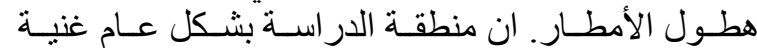

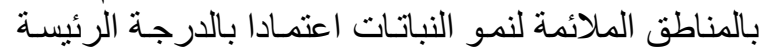

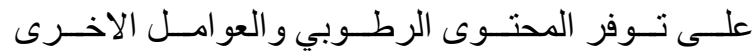

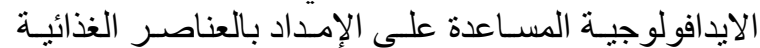

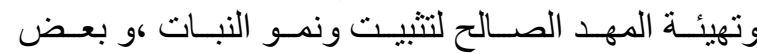

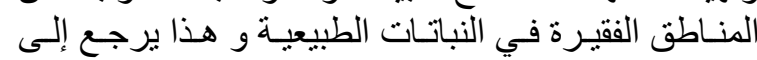

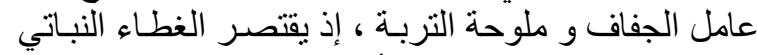

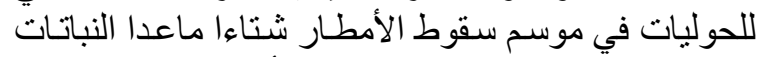

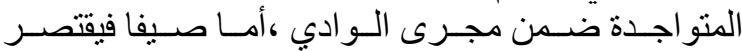

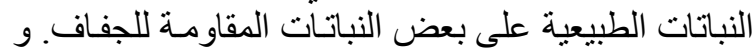

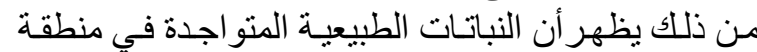

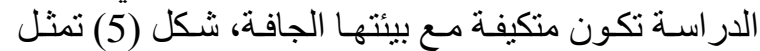
خارطة لوزيع المجتمعات النباتية، ومن الزياتيات التيات التهات الميدانية

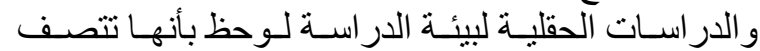

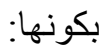

ـ الثجيرات المعمرة Perennial Shrubs الثيا:

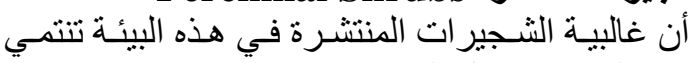

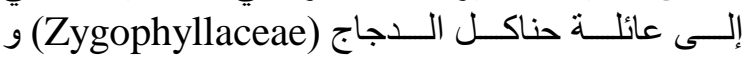
الباذنجانية (Solanaceae) و الآل (Tamaricaceae)

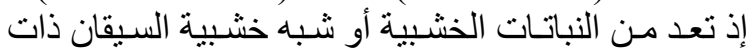

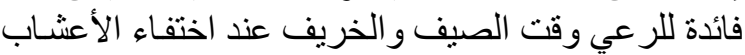

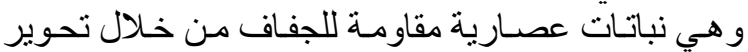

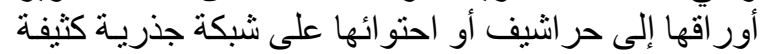

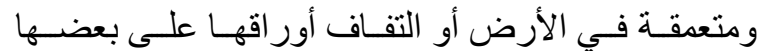

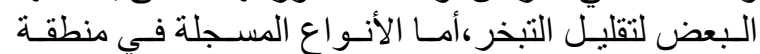

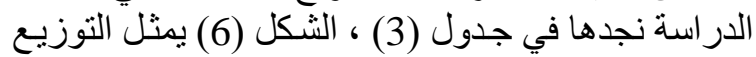

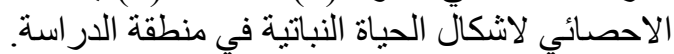
ـ الحشائش والأعشاب الحولية (Annuals Ephemerals) هذه المجمو عة من النباتات تكمل دورة حياته النها في فترة

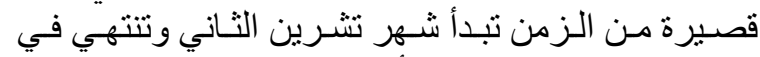

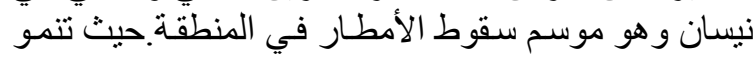

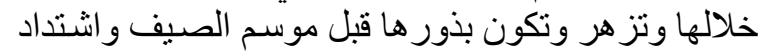

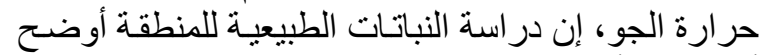

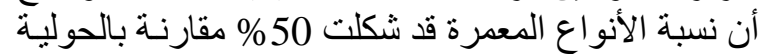

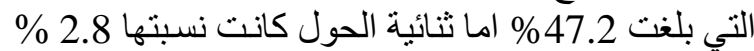

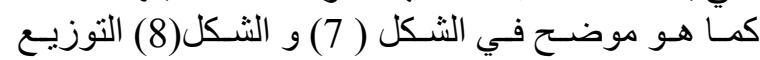

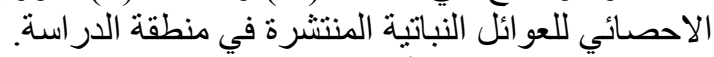

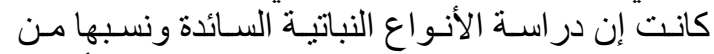

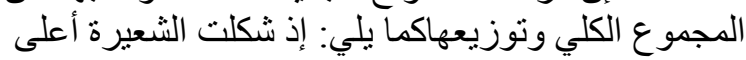

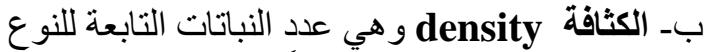
الو احد في وحدة المساحة منسوباً إلى العدد الكلي

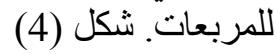

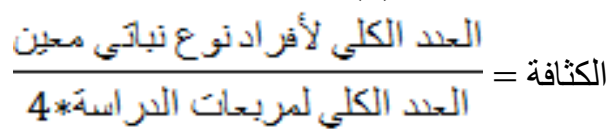

ج- التكرار Frequency of occurrence وهي النسبة المئوية لظهور احد أفراد نوع معين من النباتات نسبة إلى العدد الكلي للمربعات. التكرار=

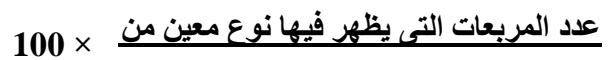

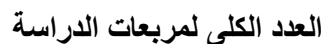

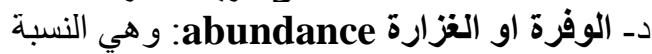

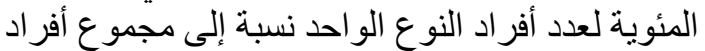
الأنو اع جميعها في عينة الدراسة. الوفرة = الانواع جيع

$100 \times$

العدد الكلى لأفز اد نوع معين من النباتات

العدد الكلى لأفراد الأنواع جميعها

هـ التغطية coverage و هي المساحة التي شغلها الجزء الخضري لأي نوع نباتي وتقاس على أساس مساحة القطع التع الناقص ellipse وحسب الصيخ نوع ونغائ التالية:

التغطية المساحية 1/4

التغطية الحجمية التهية حيث أن: D و D D Dي أقطار الجزء الخضري وط هو الارتفاع.

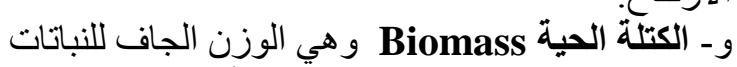

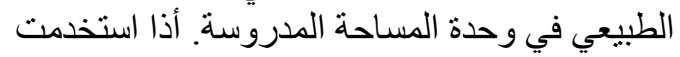

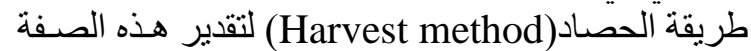

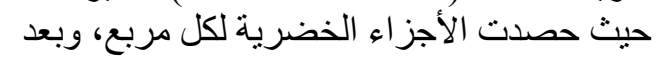

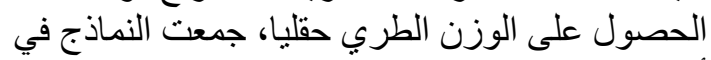

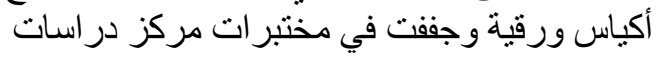

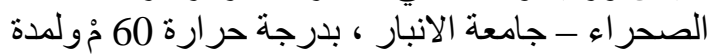

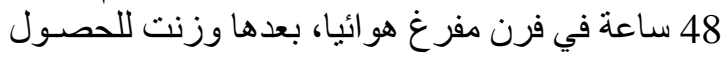
على الوزن آلجاف وحساب الكتلة الحية للنبت الطبيعي

وحسب ما ورد في Chapman و Pratt (1961).

\section{3. إنتائج و المناقشة}

$$
\text { 1.3. التنوع النباتي }
$$

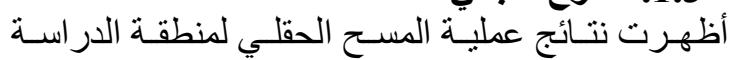

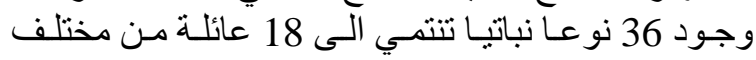

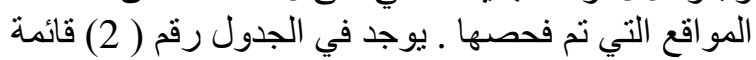

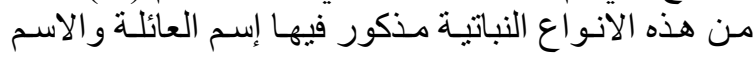

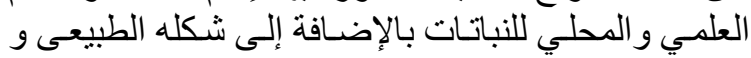
توزيعـه الجغر افى (Biogeographically regions) فضلاعن اشكال الحياه (Chorotypes) لتلك الانو اع . 
جدول (2): الأنواع التباتية المسجلة فى منطقة الدراسة و أثكال الحياة.

\begin{tabular}{|c|c|c|c|c|c|c|}
\hline $\begin{array}{c}\text { اشكال الحياة } \\
\text { (Chorotype) } \\
\text { Life Forms } \\
* *\end{array}$ & $\begin{array}{c}\text { الجغرافيع } \\
\text { Geographical } \\
\text { Distribution }\end{array}$ & $\begin{array}{c}\text { ديمومة الحياة } \\
\text { Sustainabili } \\
\text { ty of life }\end{array}$ & $\begin{array}{c}\text { التوزيع ضمقع الفيزوغرافي } \\
\text { Distribution } \\
\text { within the site } \\
\text { physiography }\end{array}$ & $\begin{array}{c}\text { الطبيعيكي } \\
\text { Natural } \\
\text { shape }\end{array}$ & $\begin{array}{l}\text { الاسليم } \\
\text { Local } \\
\text { name }\end{array}$ & $\begin{array}{c}\text { العائلة والنوع النباتي } \\
\text { Type of plant and family }\end{array}$ \\
\hline \multicolumn{7}{|c|}{ Chenopodiaceae } \\
\hline $\mathrm{Ch}$ & \multirow{4}{*}{ 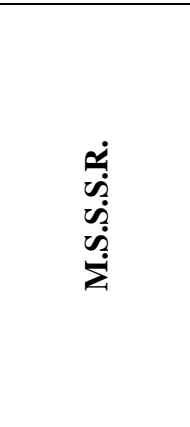 } & معمرة & مدرجات الو ادي & شغيرة & جبجاب & $\begin{array}{l}\text { Cornulaca monacantha } \\
\text { Del. }\end{array}$ \\
\hline $\mathrm{Ch}$ & & معمرة & مدرجات الو ادي & شجيرة & (خذر افض) & Salsola cyclophylla Baker \\
\hline $\mathrm{Ch}$ & & معمرة & مدرجات الوادي & شغيرة & 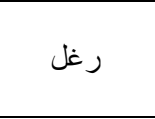 & Atriplex halimus L. \\
\hline Th & & حولي & مدرجات الوادي & عشب & ابو الشوك & Salsola kali L. \\
\hline \multicolumn{7}{|c|}{ Amaranthaceae عرف الديك } \\
\hline $\mathrm{Ch}$ & M.S.S.S.R. & معمرة & مدرجات الوادي & شجيرة & 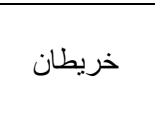 & Aerva javanica Burm. \\
\hline \multicolumn{7}{|c|}{ Primulaceae } \\
\hline Th & M.S.S.S.R. & حولى & بطن الو ادي & عشب & اذان الفارة & Anagallis arvensis $L$. \\
\hline \multicolumn{7}{|c|}{ Plantaginaceae اذان الجدي } \\
\hline Th & M.S.S.S.R. & حولى & مدرجات الو ادي & عشب & زُباد & Plantago ovate Forssk. \\
\hline \multicolumn{7}{|c|}{ Compositae } \\
\hline $\mathrm{H}$ & \multirow{5}{*}{ 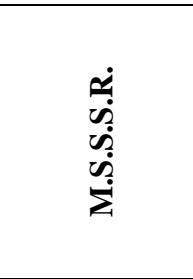 } & معمرة & مدرجات الو ادي & عشب & قيصوم & Achillea santolina $\mathrm{L}$. \\
\hline $\mathrm{Th}$ & & حولي & بطن الوادي & عشب & اقحوان البر & Calendula arvensis $\mathrm{L}$. \\
\hline $\mathrm{Ch}$ & & معرةة & بطن الوادي & عشب & كعوب & Gundeli tournefortii L. \\
\hline $\mathrm{He}$ & & 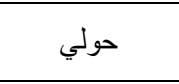 & بطن الو ادي & عشب & يمرور (لبينة & Launaea mucronata Forssk. \\
\hline Th & & 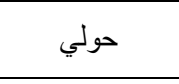 & بطن الو ومدرجات & عشب & كريص & Anthemis deserti Boiss. \\
\hline \multicolumn{7}{|c|}{ Zygophyllaceae حناكل الاجاج } \\
\hline $\mathrm{Ph}$ & M.S.S.S.R. & معمرة & بطن ومدرجات & 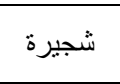 & 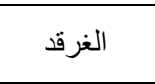 & Nitraria retusa Forssk. \\
\hline $\mathrm{He}$ & M.S.S.S.R. & معمرة & بطن الوادي & عشب & (شرشبر) & Tribulus terrestris $L$. \\
\hline \multicolumn{7}{|c|}{ Solanaceae } \\
\hline $\mathrm{Ph}$ & M.S.S.S.R. & معمرة & مدرجات الوادي & ش & (صرسج) & Lycium barbarum $\mathrm{L}$. \\
\hline $\mathrm{Ch}$ & M.S.S.S.R. & معمرة & الهضبة & عشب & المغد ال المغ & Solanum elaeagnifolium \\
\hline \multicolumn{7}{|c|}{ Scrophulanaceae حلك السبع } \\
\hline Th & M.S.S.S.R. & ثنائي الحول & الهضبة & عشب & اذان الدب & $\begin{array}{l}\text { Verbascum domascenum } \\
\text { Boiss. }\end{array}$ \\
\hline
\end{tabular}


تابع جدول (2): (2) (2)

\begin{tabular}{|c|c|c|c|c|c|c|}
\hline $\begin{array}{c}\text { اشكال الحياة } \\
\text { (Chorotype) } \\
\text { Life Forms } \\
* *\end{array}$ & $\begin{array}{c}\text { الجغزيعيع } \\
\text { Geographical } \\
\text { Distribution }\end{array}$ & $\begin{array}{c}\text { ديمومة الحياة } \\
\text { Sustainability } \\
\text { of life }\end{array}$ & $\begin{array}{c}\text { التوزيع ضمن الموقع } \\
\text { الفيزوغرافي } \\
\text { Distribution } \\
\text { within the site } \\
\text { physiography }\end{array}$ & $\begin{array}{c}\text { الطبيعي } \\
\text { Natural } \\
\text { shape }\end{array}$ & الاسم المحلي & $\begin{array}{l}\text { العائلة والنوع النباتيّ } \\
\text { Type of plant and } \\
\text { family }\end{array}$ \\
\hline \multicolumn{7}{|c|}{ Cuscutaceae } \\
\hline $\mathrm{P}$ & M.S.S.S.R. & حولي منطفل & بطن الوادي & عشب & الحامول(السرطان) & $\begin{array}{l}\text { Cuscuta chinensis } \\
\text { Lam. }\end{array}$ \\
\hline \multicolumn{7}{|c|}{ Boraginaceae لسان الثور } \\
\hline $\mathrm{Ch}$ & M.S.S.S.R. & معمرة & مدرجات الو ادي & عشب & ورد ماوي & $\begin{array}{l}\text { Anchusa strigosa } \\
\text { Banks }\end{array}$ \\
\hline Th & M.S.S.S.R. & حولي ل & مدرجات الو ادي & عشب & جحل & $\begin{array}{l}\text { Arnebia decumbens } \\
\text { (vent.) coss. }\end{array}$ \\
\hline \multicolumn{7}{|c|}{ Polygonaceae الراوندية } \\
\hline Th & M.S.S.S.R. & معمرة & بطن الوادي & عشب & عصا الر اعي & $\begin{array}{l}\text { Polygonum } \\
\text { argyrocoleum } \\
\text { steud. }\end{array}$ \\
\hline \multicolumn{7}{|c|}{ Labiatae } \\
\hline $\mathrm{He}$ & M.S.S.S.R. & معمرة & بطن الو ادي & عشب & حشيشة الكلب & $\begin{array}{l}\text { Marrabium vulgare } \\
\text { L. }\end{array}$ \\
\hline \multicolumn{7}{|c|}{ Liliaceae } \\
\hline $\mathrm{Ge}$ & M.S.S.S.R. & معمرة & بطن ومدرجات الوادي & عشب & ز إيتمان & $\begin{array}{l}\text { Gagea reticulllllata } \\
\text { Pall. }\end{array}$ \\
\hline \multicolumn{7}{|c|}{ Gramineae } \\
\hline Th & \multirow{9}{*}{$\begin{array}{l}\dot{y} \\
\dot{0} \\
\dot{0} \\
\dot{0} \\
\dot{0}\end{array}$} & حولي & بطن الوادي & عشب & رجل الحربة & $\begin{array}{l}\text { Dactyloctenium } \\
\text { aegyptium } \mathrm{L} .\end{array}$ \\
\hline Th & & حولي & بطن الوادي & عشب & رويطة & $\begin{array}{l}\text { Lolium rigidum } \\
\text { Gaudin }\end{array}$ \\
\hline $\mathrm{Ge}$ & & معمرة & بطن الوادي & عشب & خمل (ابو هدب) & Cenchrus ciliaris L. \\
\hline Th & & حولي & بطن الوادي & عشب & ادنان & $\begin{array}{l}\text { Echinochloa } \\
\text { colonum Limk }\end{array}$ \\
\hline Th & & حولي & بطن الو ادي & عشب & 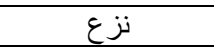 & Poa annua L. \\
\hline Th & & حولي & بطن الوادي & عشب & ركيشة (حنيطة) & $\begin{array}{l}\text { Schismus arabicus } \\
\text { Nees }\end{array}$ \\
\hline Th & & حولي الي & بطن الوادي & عشب & شعيرة & $\begin{array}{l}\text { Hordeum glaucum } \\
\text { Steud. }\end{array}$ \\
\hline Th & & حولي & بطن الوادي & عشب & ابودميم & $\begin{array}{l}\text { Phalaris minor } \\
\text { Retz. }\end{array}$ \\
\hline Th & & حولي & بطن الوادي & عشب & دوسر (شوفان) & Avena fatua $\mathrm{L}$. \\
\hline \multicolumn{7}{|c|}{ Tamaricaceae } \\
\hline $\mathrm{Ph}$ & M.S.S.S.R. & معمرة & بطن الوادي & شجيرة & الطرفة & $\begin{array}{l}\text { Tamarix } \\
\text { aucheriana Baum. }\end{array}$ \\
\hline \multicolumn{7}{|c|}{ الطلحية Mimosaceae } \\
\hline $\mathrm{Ph}$ & M.S.S.S.R. & معمرة & مدرجات الو ادي & مقزمة & خرنوب & $\begin{array}{l}\text { Prosopis forcto } \\
\text { Banks }\end{array}$ \\
\hline \multicolumn{7}{|c|}{ Papilionaceae الفراشية } \\
\hline $\mathrm{Ch}$ & M.S.S.S.R. & معمرة & بطن الو ادي & شنيرة & 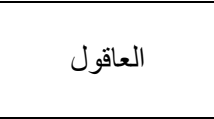 & $\begin{array}{l}\text { Alhagi graecorum } \\
\text { Boiss }\end{array}$ \\
\hline \multicolumn{7}{|c|}{ Amaranthaceae القطيفية } \\
\hline $\mathrm{Ch}$ & M.S.S.S.R. & حولي & 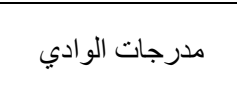 & عشب & التليث & $\begin{array}{l}\text { Halocnemum } \\
\text { strobilaceum }\end{array}$ \\
\hline
\end{tabular}




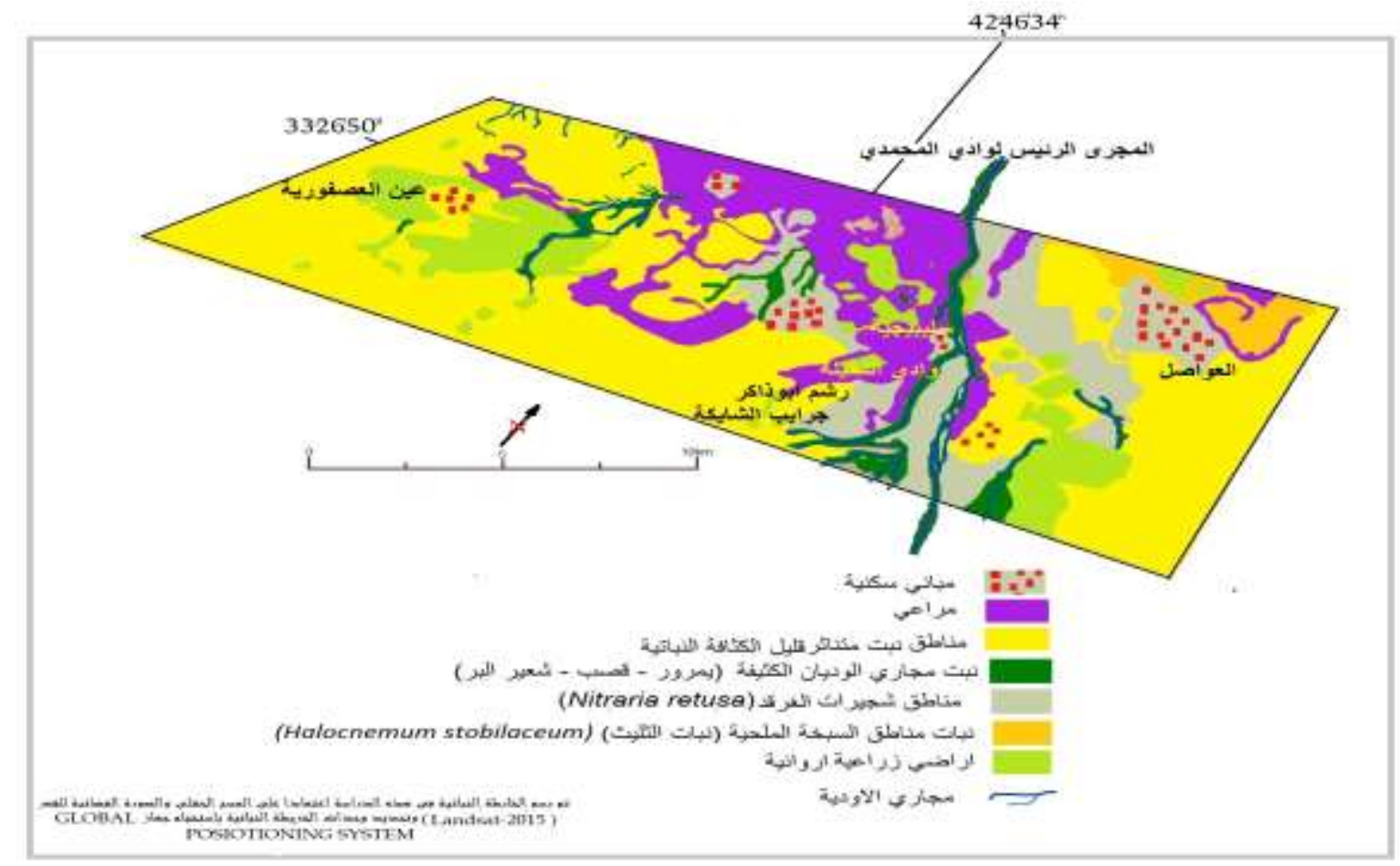

شكل (5): توزيعات الغطاءالارضي للمجتمعات النباتية لمنطقة الاراسة مسقطة على الصورة الفضائية للقمر الصناعي GLOBAL والنظام العالمي لتحديد المواقع (Landsat US Dept. of state geographer -2015) (etrex- Germany) موديل POSIOTIONING SYSTEM

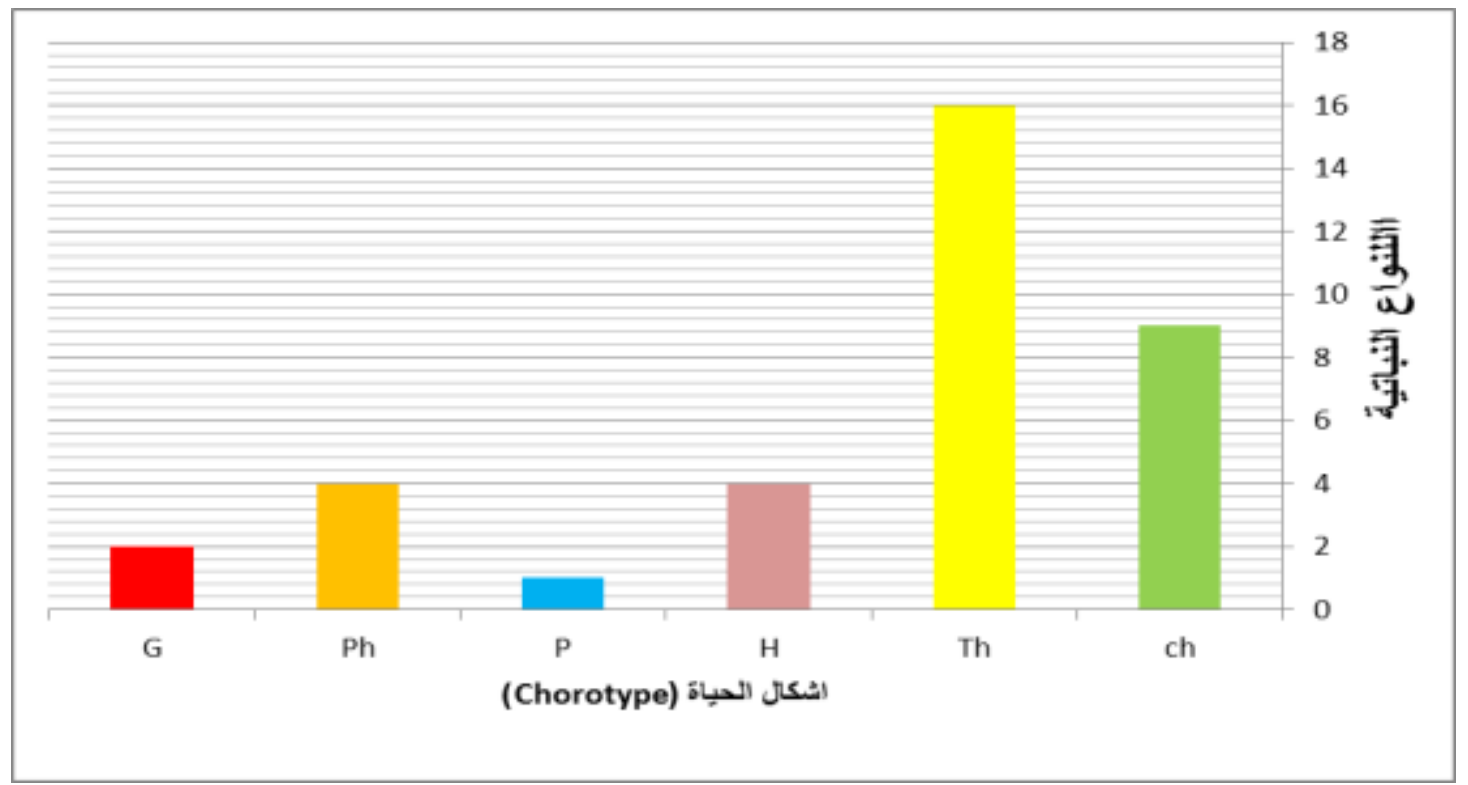

شكل (6): التوزيع الاحصائي لاشكال الحياة النباتية في منطقة الدراسة 


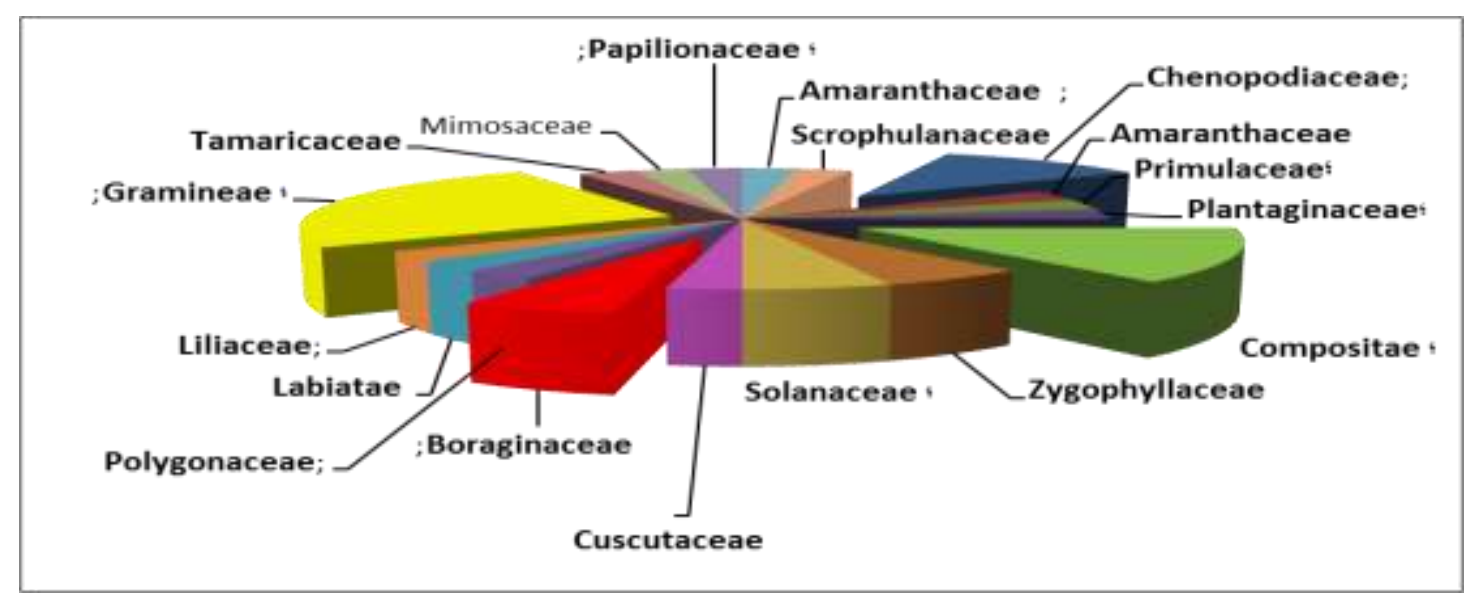

شكل (7): التوزيع الاحصائي للعوائل النباتية المنتشرة في منطقة الدراسة

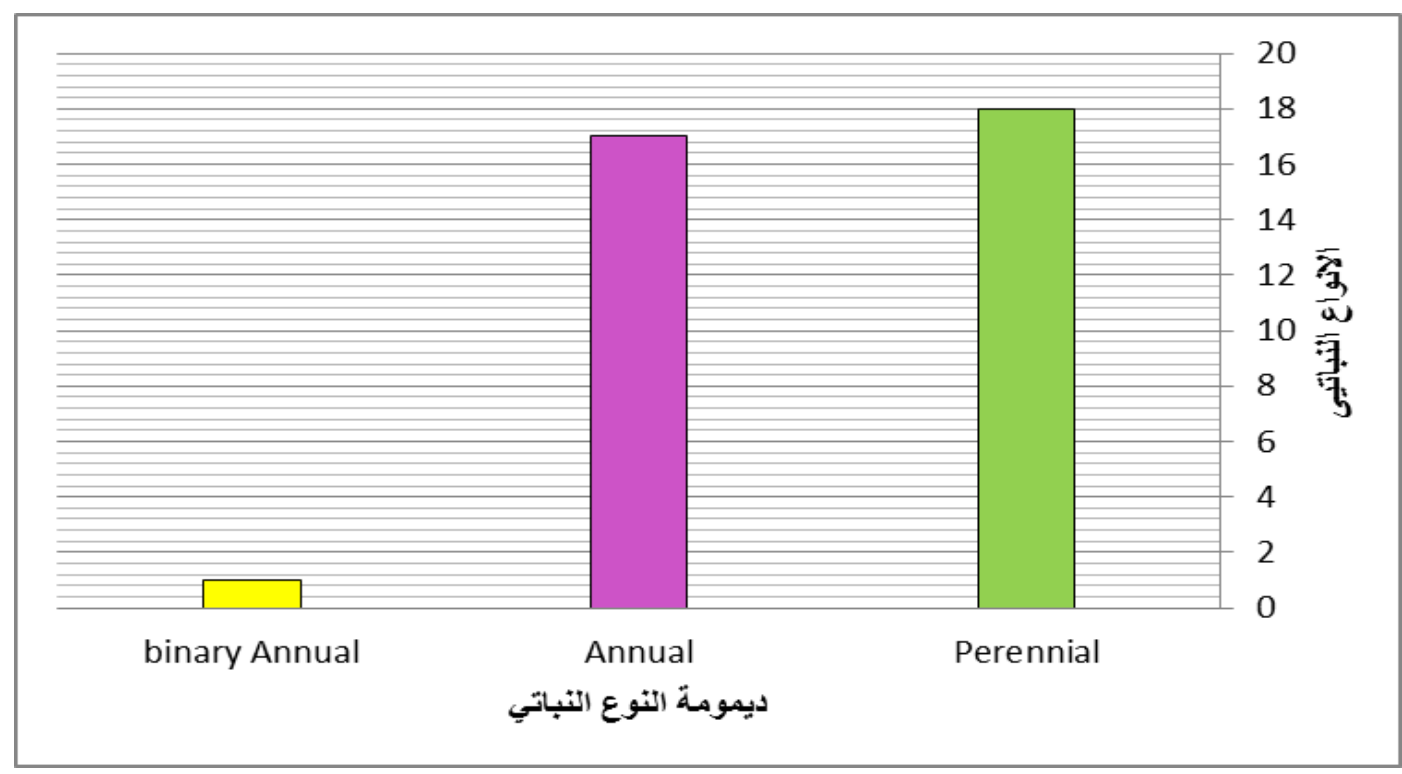

شكل (8): التوزيع النسبي للانواع النباتية الحولية والمعمرة وثنائية الحول في مواقع الاراسة.

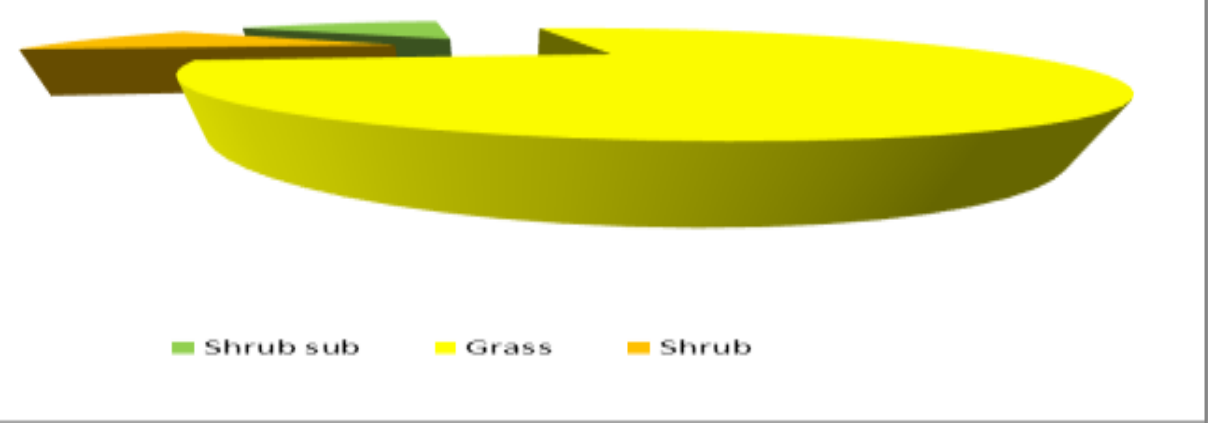

شكل (9): التوزيع النسبي للثكل الطبيعي للانواع النباتية في مواقع الاراسة. 


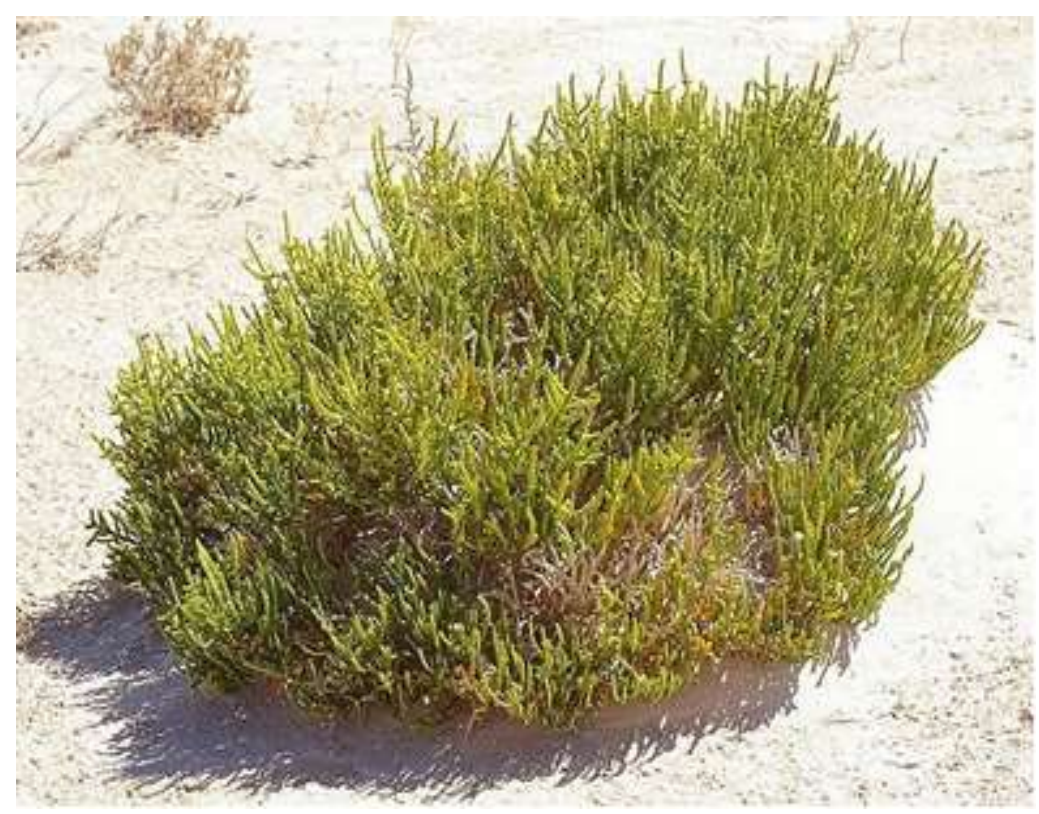

Halocnemum strobilaceum

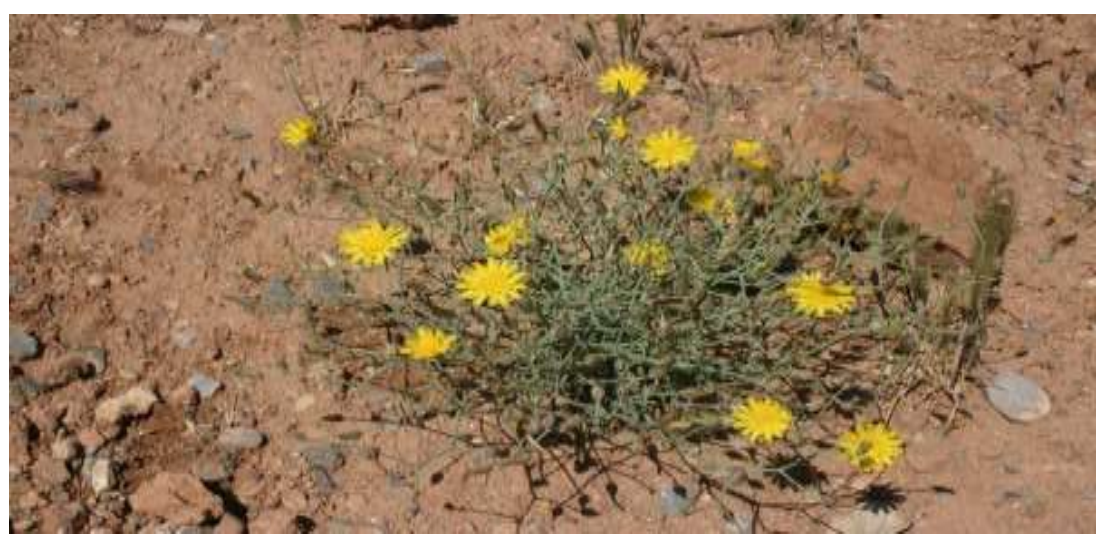

Launaea mucronata يمرور (لبينة صفرة)

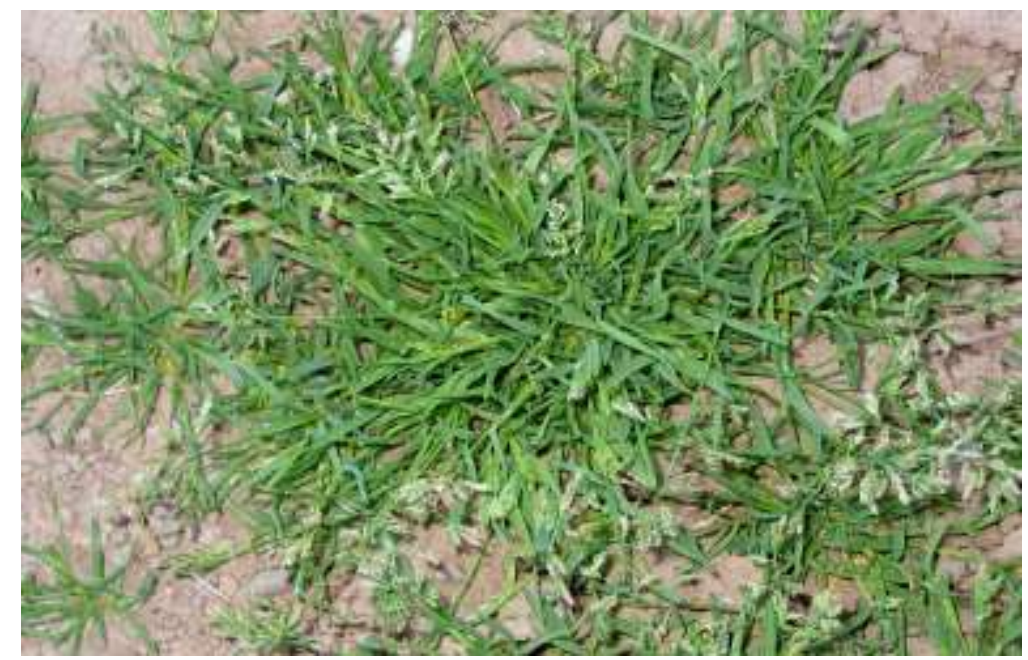

نزع Poa annua $L$.

شكل (10): نماذج من الانواع النباتي المنتشرة ضمن الوادي 


\begin{tabular}{|c|c|c|c|c|c|c|c|c|c|}
\hline \multirow{3}{*}{ 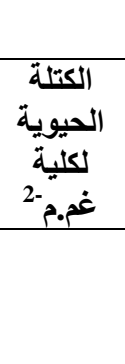 } & & \multicolumn{2}{|c|}{ التظطية coverage } & & & \multicolumn{4}{|c|}{ جدول (3): صفات الانواع النباتية بطريقة المربع . } \\
\hline & \multirow{2}{*}{ الكميوية } & \multicolumn{2}{|c|}{ coverage التغطية } & \multirow{2}{*}{$\begin{array}{l}\text { الوفرة } \\
\text { \% }\end{array}$} & \multirow{2}{*}{$\begin{array}{c}\text { التكرار } \\
\%\end{array}$} & \multirow{2}{*}{ 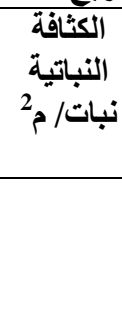 } & \multirow{2}{*}{ 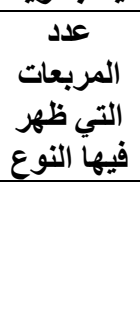 } & \multirow{2}{*}{ اللكالبيوع اللوع } & \multirow[t]{2}{*}{ النبات الطبيعي } \\
\hline & & $\begin{array}{c}\text { الحجمية } \\
\text { Volumetric } \\
\text { Volu }\end{array}$ & $\begin{array}{c}\text { المساحية } \\
\text { areal } \\
\text { areal }\end{array}$ & & & & & & \\
\hline \multirow{36}{*}{1883.9} & 19.3 & 0.031 & 0.009 & 1.45 & 12.5 & 0.5 & 2 & 4 & جبجاب \\
\hline & 14.5 & 0.050 & 0.007 & 7.29 & 31.2 & 1.0 & 5 & 20 & حض (خذراف) \\
\hline & 14.9 & 0.040 & 0.090 & 2.18 & 31.2 & 0.3 & 5 & 6 & رغل رغ \\
\hline & 10.9 & 0.070 & 0.008 & 2.55 & 31.2 & 0.35 & 5 & 7 & حمض ابوالثوك \\
\hline & 8.4 & 0.069 & 0.071 & 2.91 & 31.2 & 0.4 & 5 & 8 & خريطان \\
\hline & 13.5 & 0.020 & 0.020 & 1.45 & 18.7 & 0.33 & 3 & 4 & اذأن الفارة \\
\hline & 9.5 & 0.070 & 0.050 & 5.47 & 37.5 & 0.62 & 6 & 15 & زَبَاد \\
\hline & 17.5 & 0.080 & 0.050 & 1.82 & 25.0 & 0.31 & 4 & 5 & 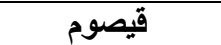 \\
\hline & 7.0 & 0.031 & 0.004 & 1.82 & 12.5 & 0.62 & 2 & 5 & اقحوان البر \\
\hline & 17.2 & 0.050 & 0.075 & 1.82 & 18.7 & 0.41 & 3 & 5 & كعوب كوب \\
\hline & 14.3 & 0.040 & 0.041 & 7.29 & 50.0 & 0.62 & 8 & 20 & يمرور(لبينةتصفر \\
\hline & 7.2 & 0.070 & 0.005 & 2.91 & 50.0 & 0.25 & 8 & 8 & كريص \\
\hline & 665.5 & 0.060 & 0.190 & 2.91 & 31.2 & 0.40 & 5 & 8 & 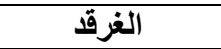 \\
\hline & 10.1 & 0.020 & 0.089 & 4.37 & 43.7 & 0.42 & 7 & 12 & كطب (شرشير) \\
\hline & 800.2 & 0.070 & 0.051 & 2.91 & 25.0 & 0.5 & 4 & 8 & عوستج (صريم) \\
\hline & 14.5 & 0.080 & 0.210 & 2.18 & 43.7 & 0.21 & 7 & 6 & 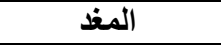 \\
\hline & 14.6 & 0.031 & 0.030 & 18.7 & 18.7 & 0.41 & 3 & 5 & اذذان الدب \\
\hline & 12.3 & 0.030 & 0.040 & 0.36 & 6.25 & 0.25 & 1 & 1 & الحامول(السرطا \\
\hline & 4.9 & 0.012 & 0.007 & 0.72 & 6.25 & 0.50 & 1 & 2 & ورد ماوي \\
\hline & 5.5 & 0.001 & 0.090 & 1.45 & 12.5 & 0.50 & 2 & 4 & جحل ج ج ج \\
\hline & 6.9 & 0.028 & 0.050 & 1.09 & 25.0 & 0.04 & 4 & 3 & عصا الراعي \\
\hline & 9.5 & 0.041 & 0.050 & 1.09 & 12.5 & 0.37 & 2 & 3 & حشيشة الكلب \\
\hline & 8.5 & 0.009 & 0.010 & 1.0 & 18.7 & 0.16 & 3 & 2 & زعيتمان \\
\hline & 4.9 & 0.090 & 0.020 & 1.09 & 25.0 & 0.18 & 4 & 3 & رجل الحربة \\
\hline & 3.9 & 0.030 & 0.014 & 2.18 & 31.2 & 0.3 & 5 & 6 & رويطة \\
\hline & 9.3 & 0.008 & 0.005 & 0.72 & 25.0 & 0.12 & 4 & 2 & خمل (ابو هلب) \\
\hline & 4.6 & 0.030 & 0.040 & 1.09 & 25.0 & 0.18 & 4 & 3 & 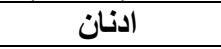 \\
\hline & 7.0 & 0.090 & 0.005 & 1.45 & 31.2 & 0.20 & 5 & 4 & نزع \\
\hline & 10.0 & 0.080 & 0.090 & 2.18 & 25.0 & 0.37 & 4 & 6 & ركيشة (حنيطة) \\
\hline & 12.6 & 0.091 & 0.007 & 9.12 & 43.7 & 0.89 & 7 & 25 & 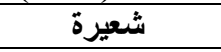 \\
\hline & 17.2 & 0.070 & 0.009 & 1.45 & 18.7 & 0.33 & 3 & 4 & 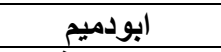 \\
\hline & 9.5 & 0.049 & 0.008 & 18.7 & 25.0 & 0.31 & 4 & 5 & دوسر (شوفان) \\
\hline & 40.6 & 0.099 & 0.080 & 2.91 & 31.2 & 0.40 & 5 & 8 & طرفة \\
\hline & 12.3 & 0.095 & 0.040 & 5.83 & 37.5 & 0.66 & 6 & 16 & خرنوب \\
\hline & 14.5 & 0.090 & 0.019 & 5.47 & 50 & 0.46 & 8 & 15 & العاقول \\
\hline & 30.5 & 0.093 & 0.017 & 5.83 & 31.2 & 0.8 & 5 & 16 & الثليث \\
\hline
\end{tabular}


الظلال الو اسعة في وجود بساتين النخيل ومو اقع ترفيه

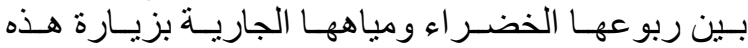

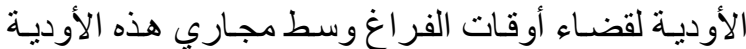

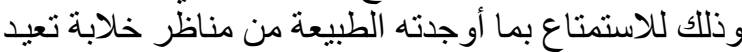

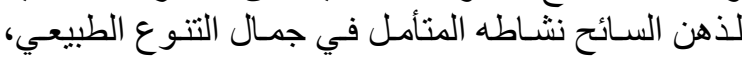

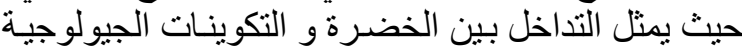

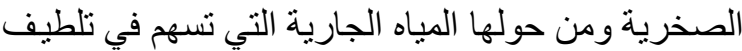

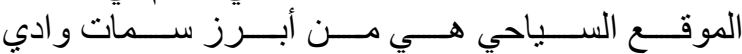

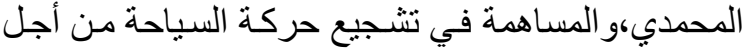
الإطلاع وحب المغامرة وسط معالم سياحية فريدة.

\section{4. - المراجع العربية}

إبن مسعود، فهد حمد ابر اهيم ـ (2008). دراسات بيئية الإية تصنيفية لروضة الأحور في المنطقة الوسطى الهي

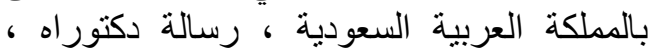

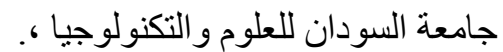

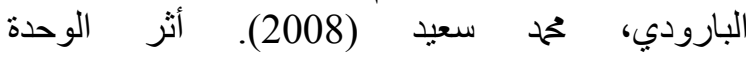

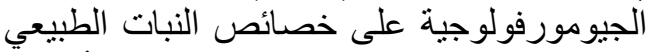
الثجري في البيئة الجافة دراسة حالة لألة لأودية

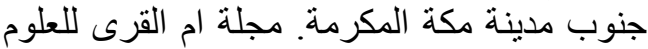

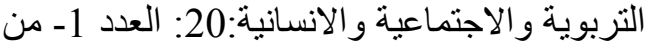

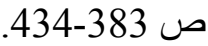

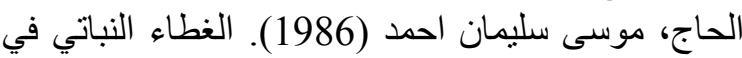
حوض وادي شعيب . رسالة ماجستير .الجامعة النية

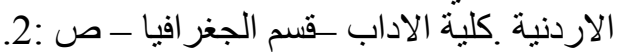

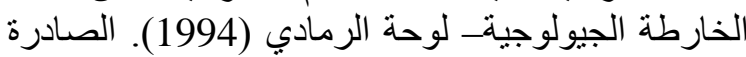
من الهيئة العامة للمسح الجيولوجي والرئ والتحري

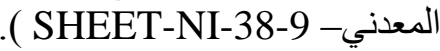
الخطيب، محمد محيب الدين (1978). المر اعي الصحر اوية الزية

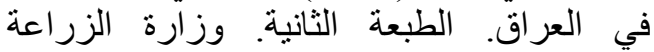
والإصلاح الزراعي - مديرية المراعي الطبيعية

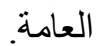
العلواني، عبد الكريم أحمد مخيلف (2007). تأثير الاستغلال الزراعي في صفات التربة والنبت التبت

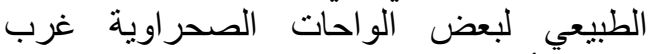
العر اق. أطروحة دكتور اه. كلية الزراعة الهرات - جامعة غربة

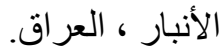

المركز العربي لدراسات العناطق الجافة المافة والأراضي

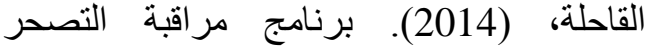

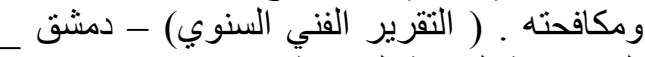

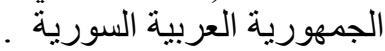

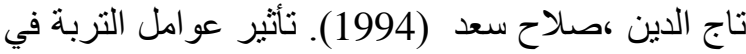

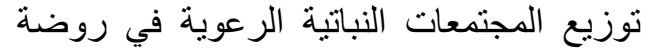

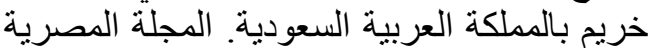
للعلوم النطبيقية ، 71 :9(10)، 69-82.
نسبة (9.1\%) يليه اليمرور والحمض (الخذراف) بنسبة7.2\% لكل منهما ثم الثليث و الخرنوب بنسبة 5.8\% لكل منهما و أخيرا الزُباد وبنسب توزيع 5.4 5.

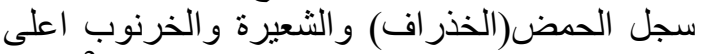

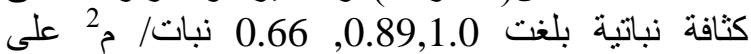

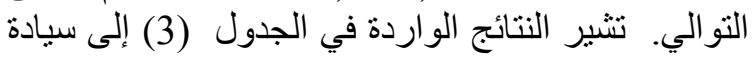

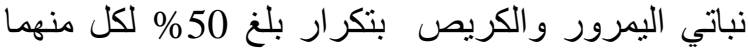

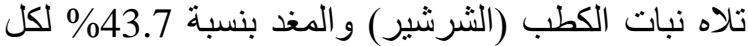
منهما و الزباد 37.2\% وقد وات حازت كل من نباتات الرغل

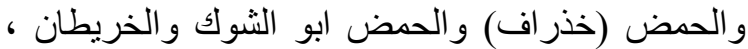

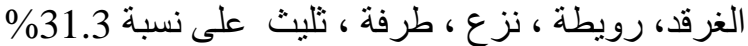

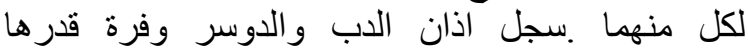
\%.7\% لكل منهم ، اما نبات الشعيرة بلغت وفرة وفرتها \%9.12, و ادنى قيمة للوفرة سجلها نبات ورد ماوي بنسبة لفنات

إن نواجد الرغل في هذه البيئة تتفق مع ما أثنار إليه Guest (1966 و الخطيب (1978) إذ يتو اجد هذا النبات

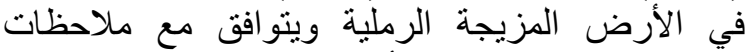
Thalen المنطقة الغربية من العراق. وكذلك ما لاحت الاحظه العلواني

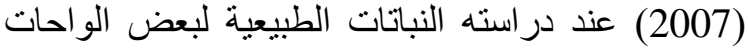

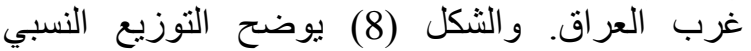

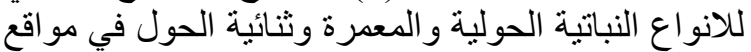

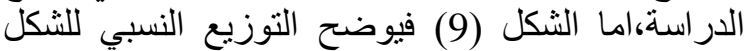

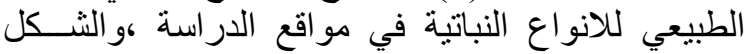
(10) يمثل صور نماذج من الانواعة في النع النباتية المنتشرة

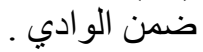

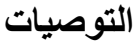

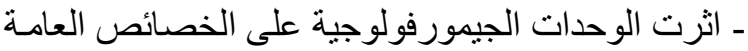

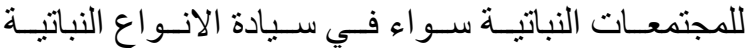

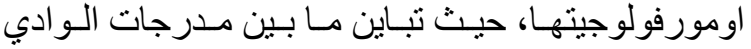

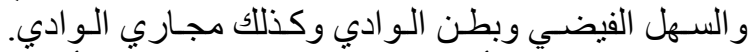

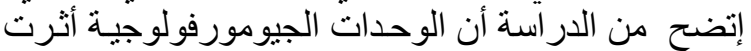

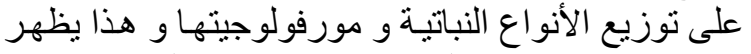

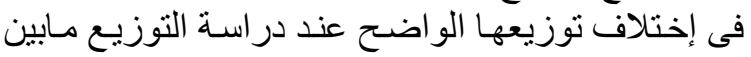

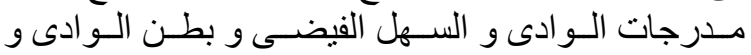

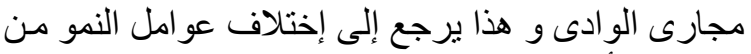

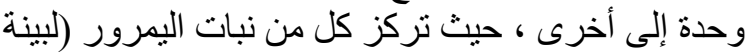

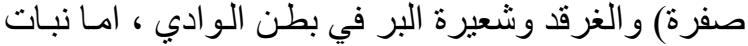

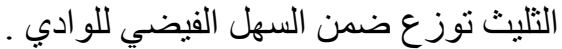

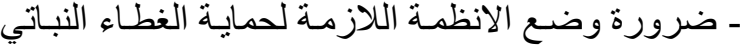

من التدهور وخاصة مدرجات الو ادي و الاودية الفية الفرعية.

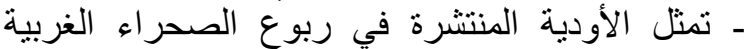

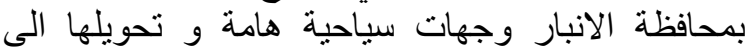

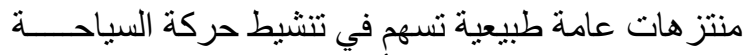

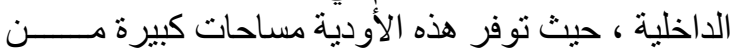




\section{REFERENCES}

Agnew A. D. Q. (1960). The protected range areas at Khidr el mai and Shubaichi. Report to Dir. Gen. Res. and projects, Min. Agric., Iraq, 7 pp. (typescript) .

Barbour M.G., Burk J. and Pitts. W.D. (1980). Terrestrial Plant Ecology. The Benjamin Cummings publ. company. Inc. USA.

Cain S.A. and Castro G.M.(1959). Manual of vegetation analysis. Harper, New York.

Chapman H. D. and Pratt P. F.(1961). Methods of analysis for soils, plants and waters . Univ. of Calif. Agric., Berkeley . USA.309 pp.

Guest E. R. (1966). Flora of Iraq. Volume one .Introduction to the Flora, An Account of the Geology, Soils, Climate and ecology of Iraq with Gazetteer , glossary and Bibliography. Min. Agric. Iraq, 313 pp.

Hamza N.M. and Latif S.A. (1975). Report on the regional geological mapping of Al-Therthar Hit-Qasr Alkhubbaz. Area General Directorate for Geological Survey and Mineral investigation, Geological Survey department, Baghdad, Iraq.p.39.
Kaul R.N. and AlMufti M.M. (1974). Range Resources of Iraq X1. A Perliminary ecological appraisal of Artemisia herba-alba vegetation. Tech. Rep. No.55. Inst.for Appl.

Laurence A. Stoddare, Arthur D. Smith and Thadis W. Box (1975). Range Management. McGraw-Hill Book Company, New York,USA.

Sissakian V.K., Mahdi A.I., Amin R.M. and Salman B.M. (1997). The Nfayil Formation: A new lithostratigraphic unit in the Western Desert of Iraq. Iraqi Geol, Jour., Vol.30, No. 1, pp.61-65.

Varoujan K.,Sissakian V.K. and Buthaina S. Mohammed (2007). Stratigraphy, Iraqi Bulletin of Geology and Mining، Special Issue: Geology of Iraqi Western Desert. State company of Geological Survey and Mining, p.105.

Wilson E.O. (2004). Introduction to Biodiversity. In: Biodiversity II, Understanding and Protecting Our Biological Resources. Kudla M. Wilson D. E. Wilson E. O. (eds), Joseph Henry Press, Washington D. C. 559 p. 